Article

\title{
Concept and Performance Evaluation of a Novel UAV-Borne Topo-Bathymetric LiDAR Sensor
}

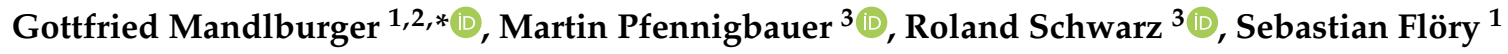 \\ and Lukas Nussbaumer ${ }^{1}$ \\ 1 Department of Geodesy and Geoinformation, TU Wien, Wiedner Hauptstr. 8-10, 1040 Vienna, Austria; \\ sebastian.floery@geo.tuwien.ac.at (S.F.); lukas.nussbaumer@student.tuwien.ac.at (L.N.) \\ 2 Institute for Photogrammetry, University of Stuttgart, Geschwister-Scholl-Str. 24D, 70174 Stuttgart, Germany \\ 3 Riegl Research Forschungs Gesellschaft mbH, Riedenburgstr. 48, 3580 Horn, Austria; \\ martin.pfennigbauer@riegl.co.at (M.P.); roland.schwarz@riegl.co.at (R.S.) \\ * Correspondence: gottfried.mandlburger@geo.tuwien.ac.at; Tel.: +43-1-58801-12235
}

Received: 15 February 2020; Accepted: 13 March 2020; Published: 19 March 2020

\begin{abstract}
We present the sensor concept and first performance and accuracy assessment results of a novel lightweight topo-bathymetric laser scanner designed for integration on Unmanned Aerial Vehicles (UAVs), light aircraft, and helicopters. The instrument is particularly well suited for capturing river bathymetry in high spatial resolution as a consequence of (i) the low nominal flying altitude of 50-150 m above ground level resulting in a laser footprint diameter on the ground of typically $10-30 \mathrm{~cm}$ and (ii) the high pulse repetition rate of up to $200 \mathrm{kHz}$ yielding a point density on the ground of approximately $20-50$ points $/ \mathrm{m}^{2}$. The instrument features online waveform processing and additionally stores the full waveform within the entire range gate for waveform analysis in post-processing. The sensor was tested in a real-world environment by acquiring data from two freshwater ponds and a $500 \mathrm{~m}$ section of the pre-Alpine Pielach River (Lower Austria). The captured underwater points featured a maximum penetration of two times the Secchi depth. On dry land, the 3D point clouds exhibited (i) a measurement noise in the range of 1-3 $\mathrm{mm}$; (ii) a fitting precision of redundantly captured flight strips of $1 \mathrm{~cm}$; and (iii) an absolute accuracy of 2-3 cm compared to terrestrially surveyed checkerboard targets. A comparison of the refraction corrected LiDAR point cloud with independent underwater checkpoints exhibited a maximum deviation of $7.8 \mathrm{~cm}$ and revealed a systematic depth-dependent error when using a refraction coefficient of $n=1.36$ for time-of-flight correction. The bias is attributed to multi-path effects in the turbid water column (Secchi depth: $1.1 \mathrm{~m}$ ) caused by forward scattering of the laser signal at suspended particles. Due to the high spatial resolution, good depth performance, and accuracy, the sensor shows a high potential for applications in hydrology, fluvial morphology, and hydraulic engineering, including flood simulation, sediment transport modeling, and habitat mapping.
\end{abstract}

Keywords: UAV LiDAR; airborne laser bathymetry; full waveform processing; performance assessment; high resolution hydro-mapping

\section{Introduction}

The introduction of Unmanned Aerial Vehicles (UAV), also referred to as Unmanned Aerial Systems (UAS), as platforms for the acquisition of high-resolution 3D data has fundamentally changed the mapping sector in recent years. UAVs flying at low altitudes combine the advantages of small sensor-to-object distances (i.e., close range) and agility. The latter is achieved via remotely controlling the unmanned sensor platform either manually by a pilot within the Visual Line-Of-Sight (VLOS) or by autonomously flying predefined routes based on waypoints, allowing both within and beyond VLOS operation. 
UAV-based 3D data acquisition was first accomplished using light-weight camera systems, where advancements in digital photogrammetry and computer vision-enabled automatic data processing workflows for the derivation of dense 3D point clouds based on Structure-from-Motion (SfM) and Dense Image Matching (DIM). Due to advancements in UAV-platform technology and ongoing sensor miniaturization, today compact LiDAR sensors are increasingly integrated on both multi-copter and fixed-wing UAVs, enabling 3D mapping with unprecedented spatial resolution and accuracy. The tackled applications include topographic mapping, geomorphology, infrastructure inspection, environmental monitoring, forestry, and precision farming. While UAV-borne laser scanning (ULS) can already be considered state-of-the-art for mapping tasks above the water table, UAV-based bathymetric LiDAR still lacks behind, mainly due to payload restrictions.

The established techniques for mapping bathymetry are single- or multi-beam echo sounding (SBES/MBES), including Acoustic Doppler Current Profiling (ADCP). This holds for both coastal and inland water mapping. MBES is the prime acquisition method for area-based charting of water bodies deeper than approximately two times the Secchi depth (SD), and the productivity of this technology is best in deeper water because the width of the scanned swath increases with water depth. For mapping shallow water bathymetry including shallow running waters, boat-based echo sounding is less productive and furthermore, safety issues arise. For relatively clear and shallow water bodies, airborne laser bathymetry (ALB) constitutes a well-proven alternative. This active, optical, polar measurement technique features the following advantages: (i) areal coverage only depending on the flying height but not on the water depth; (ii) homogeneous point density; (iii) simultaneous mapping of water bottom, water surface, and dry land area in a single campaign, referred to as topo-bathymetric LiDAR; and (iv) non-contact remote sensing approach with clear benefits for mapping nature conservation areas.

ALB performed from manned platforms [1] has a long history in under-water object detection and charting of coastal areas including characterization of benthic habitats [2]. In the recent past, the technology is increasingly used for inland waters [3-5]. In order to ensure eye safety, the employed laser beam divergence is typically in the range of 1-10 mrad. For a typical flying altitude of $500 \mathrm{~m}$ or higher the resulting laser footprint diameter on the ground measures at least 50-500 cm. Thus, the spatial resolution of ALB from manned aerial platforms is limited. Due to the shorter measurement ranges, ULS promises a better resolution and allows users to capture and reconstruct smaller structures like boulders, submerged driftwood, and the like, with potential applications for the characterization of flow resistance in hydrodynamic numerical (HN) models.

To date, only a few UAV-borne LiDAR sensors are available. The RIEGL BathyDepthFinder is a bathymetric laser range finder with a fixed laser beam axis (i.e., no scanning). Like most of the bathymetric laser sensors, the system utilizes a green laser $(\lambda=532 \mathrm{~nm})$ and allows for the capture of river cross-sections constituting an appropriate input for 1D-HN models. The ASTRALiTe sensor is a scanning polarizing LiDAR [6]. The employed $30 \mathrm{~mW}$ laser only allows low flying altitudes and therefore provides limited areal measurement performance and the depth performance is moderate (1.2 -fold SD). The RAMMS (Rapid Airborne Multibeam Mapping System) was recently developed by Fugro Inc. and Areté Associates [7]. It is a relatively lightweight, $14 \mathrm{~kg}$ push-broom ALB sensor featuring a measurement rate of $25 \mathrm{kHz}$ and promising a penetration performance of $3 \mathrm{SD}$ according to the company's web site [8]. The sensor is operated by Fugro for delivering high-resolution bathymetric services, but independent performance and accuracy assessments are not available.

In 2018, RIEGL introduced the VQ-840-G, a lightweight topo-bathymetric full-waveform scanner [9] with a maximum pulse repetition rate (PRR) of $200 \mathrm{kHz}$. The scanner is designed for installation on various platforms including UAVs and carries out laser range measurements for high resolution, survey-grade mapping of underwater topography with a narrow, visible green laser beam. The system is optionally offered with an integrated and factory-calibrated IMU/GNSS system, and with an optional camera or IR rangefinder. As such, it constitutes a compact, comprehensive, and full-featured ALB system for mapping coastal and inland waters from low flying altitudes. 
The inherent advantage of such a design is twofold: (i) the short measurement ranges and high scan rates enable surface description in high spatial resolution as a consequence of high point density and relatively small laser footprint; and (ii) integration on UAV platforms or lightweight manned aircraft reduces mobilization costs and enables agile data acquisition. In the context of ALB, the prior holds out the prospect of reconstructing submerged surface details below the size of boulder (i.e., dm-level) which is not feasible from flying altitudes of $500 \mathrm{~m}$ or higher due to the large laser footprint diameter, and the latter is especially beneficial for capturing medium-sized, meandering running waters with moderate widths $(<50 \mathrm{~m})$ and depth $(<5 \mathrm{~m})$ which would require a complex flight plan with many potentially short flight strips and a multitude of turning maneuvers for a conventional manned ALB survey. Thus, UAV-borne bathymetric LiDAR is considered a major leap forward for river mapping with an expected positive stimulus on a variety of hydrologic and hydraulic applications like flood risk simulations, sediment transport modeling, monitoring of fluvial geomorphology, eco-hydraulics, and the like.

In this article, we present the first rigorous accuracy and performance assessment of a UAV-borne ALB system by evaluating the 3D point clouds acquired at the pre-Alpine Pielach River and an adjacent freshwater pond. We compare the LiDAR measurements with ground truth data obtained from terrestrial survey with a total station in cm-accuracy and provide objective measures describing the precision, accuracy, and depth performance of the system. Furthermore, we discuss the fields of application, limits, and challenges of UAV-borne LiDAR bathymetry including potential fusion with complementary sensors (RGBI cameras, thermal IR cameras), widening the scope beyond pure bathymetric mapping towards discharge estimation, flow resistance characterization, etc.

Our main contribution is providing an in-depth evaluation of topo-bathymetric UAV-LiDAR including a discussion of limitations on the one side and benefits compared to manned ALB on the other side. Next to accuracy and performance assessment, our focus is on an objective evaluation of achievable spatial resolution, especially addressing the question to which extent the shorter measurement ranges and smaller nominal laser footprints directly induce higher resolution. Furthermore, we put the presented full-waveform scanner in context with existing line scanning technologies.

The remainder of the manuscript is structured as follows. In Section 2, we review the state-of-the-art in UAV-based bathymetry followed by a description of the senor concept in Section 3 . Section 4 introduces the study area and existing datasets, and details the employed data processing and assessment methods. The evaluation results are presented in Section 5 along with critical discussion in Section 6. The paper concludes with a summary of the main findings in Section 7.

\section{Related Work}

In this Section, we provide a summary of related work in the context of UAV-based optical remote sensing of coastal and inland water areas, focusing on the derivation of bathymetry. For the sake of completeness, we first briefly discuss passive image-based techniques, both via multimedia photogrammetry [10] and spectrally based depth estimation [11], but mainly concentrate on bathymetric LiDAR [1] in general and small-footprint topo-bathymetric LiDAR for inland water applications in particular $[12,13]$. Furthermore, we present recent validation and comparison studies on subject matters as our contribution also focuses on sensor evaluation.

\subsection{UAV-Borne Multimedia Photogrammetry}

The advent of UAVs as carrier platforms of active and passive mapping sensors had a huge impact in the field of photogrammetry and remote sensing [14]. The introduction of Structure-from-Motion (SfM) and Dense Image Matching (DIM) techniques providing automatic orientation of entire image blocks and height estimates for every image pixel $[15,16]$ has democratized image-based 3D mapping of topography and dramatically increased the achievable point densities $[17,18]$. The applicability of UAV-photogrammetry is further facilitated due to the existence of easy-to-use software solutions 
providing an automated processing chain from captured images to digital surface models, 3D meshes, and orthophoto maps, respectively [19-21].

While the application of SfM is directly applicable for the dry part of alluvial and coastal areas [22,23], mapping of underwater topography requires consideration of beam bending at the air-water medium boundary. Ref. [24] describes the basic principles of multimedia photogrammetry and the authors of [25] provide an early evaluation of the technique for mapping a clear and shallow gravel-bed river. More recently, Ref. [26,27] focused on fluvial and aquatic applications of SfM based on UAV imagery emphasising the unprecedented spatio-temporal coverage [27] and the necessity of automated procedures for refraction correction [26]. The latter is crucial for obtaining accurate depth measurements but is difficult to achieve because image-based reconstruction of natural water surfaces poses problems due to the general prerequisite of transparent water conditions. In this context, Refs. [28-30] propose a deep-learning-based framework to automatically correct refraction effects in SfM and multi-view stereo processing pipelines.

As for every optical method aiming at mapping bathymetry, clear water is a precondition for the successful application of multimedia photogrammetry. In addition, Ref. [31] discusses further prerequisites for exploiting the potentially high spatial resolution of mapping shallow water bathymetry via through-water dense image matching. It is concluded that sufficient bottom texture and favorable calm water surfaces are prerequisites for achieving accurate results, as image matching is heavily distorted in wavy surface conditions and spatial aggregation (i.e., low pass filtering) is necessary to suppress high-frequency noise. This, however, limits the spatial resolution to the $1 \mathrm{~m}$-level, even for UAV-imagery featuring a ground sampling distance (GSD) in the cm-range.

\subsection{UAV-Borne Spectrally Based Depth Estimation}

The foundations of mapping bathymetry from multi-spectral images are described in [11,32-35]. The main application of this technique, which uses either physical models or regression techniques to relate the spectral information of one or more color channels to water depth, is Satellite-Derived Bathymetry (SDB) based on multispectral remote sensing sensors like Landsat 8, WorldView-2, etc. [36,37]. While the resolution of SDB bathymetry is inherently limited by the GSD of satellite images, high-resolution applications of this technique based on hyperspectral UAV imagery was recently reported by [38]. The authors demonstrate the potential for bathymetric mapping at cm-resolution and approximately dm-accuracy. However, transient water surfaces negatively affect the achievable accuracy as discussed in Section 2.1.

\subsection{UAV-Borne Bathymetric LiDAR}

Scanning bathymetric LiDAR from manned airborne platforms, commonly referred to as Airborne Laser Bathymetry (ALB), suffers from low spatial resolution. In order to ensure eye-safe operation, the employed visible green laser beams are generally broader compared to lasers using infrared laser radiation for mapping topography. This applies to both so-called deep bathy sensors [1] with a typical beam divergence of $5 \mathrm{mrad}$ as well as for relatively small-footprint topo-bathymetric laser scanners $[3,12,39]$ employing a beam divergence of around $1 \mathrm{mrad}$. For the latter, the footprint diameter at a typical flying altitude of $600 \mathrm{~m}$ still features a size of $60 \mathrm{~cm}$, thus limiting the achievable planimetric resolution to the m-level. One of the main advantages of UAV-borne LiDAR bathymetry is, therefore, the potentially higher planimetric resolution. In the following, we review available sensors that are lightweight enough to be carried by multi-copter and even fixed-wing UAV platforms. Most of the instruments were just recently introduced, thus only a few scientific articles are published yet. This is the reason why our review is mainly based on company websites, sensor spec sheets, and recent publications in technical journals reporting about emerging trends [40]. 
- ASTRALite edge $e^{\mathrm{TM}}$ : This sensor features a weight of $5 \mathrm{~kg}$ and a PRR of $20 \mathrm{kH}$ [41]. The manufacturer states a precision/accuracy of $5 / 10 \mathrm{~mm}$ and a depth penetration of $>1.5 \mathrm{SD}$ at a typical flying altitude for mapping bathymetry of $20 \mathrm{~m}$. To overcome the known problem of separating signals from the surface and the bottom beneath, signal processing is based on a technique known as INtrapulse Phase Modification Induced by Scattering (INPHAMIS) considering the polarization of the returned laser pulses [6,42]. Show-cases of this sensor, which can be mounted on standard multi-copter UAV platforms like the DJI Matrice 600, are reported in [43-45]. The authors of [46] use the instrument for UAV-based discharge estimation requiring flow velocity but also precise river bed geometry data. A current drawback of the sensor is its relatively low flying altitude resulting in a poor areal coverage performance.

- Fugro RAMMS: Fugro's topo-bathymetric UAV laser scanner avoids moving parts by employing a pushbroom scanning technique [47]. RAMMS (Rapid Airborne Multibeam Mapping System) is a successor of PILLS (Pushbroom Imaging LIDAR for Littoral Surveillance) developed by Areté Associates [48], which was first introduced in 2012. Instead of single laser pulses deflected by a rotating or oscillating mirror, a laser line is emitted and the backscattered signal is captured by a camera receiver. The compact sensor (weight: $14 \mathrm{~kg}$ ) is designed for integration in small aircraft or larger UAVs, delivers $25 \mathrm{~K}$ range observations per second, and achieves $3 \mathrm{SD}$ penetration $[8,49]$. Successful completion of large-area bathymetric mapping projects (area: $10 \mathrm{~K} \mathrm{~km}^{2}$ ) carried out in very clear coastal waters are reported in [7]. The survey was conducted from a flying altitude of $325 \mathrm{~m}$ resulting in an across-track point spacing of $33 \mathrm{~cm}$. The mission parameters are optimized for large area coverage, but similar point densities can also be achieved with standard topo-bathymetric sensors [4]. Higher spatial resolution is generally feasible by integrating the sensor on UAV platforms [47], but to the best of our knowledge, respective reports have not been published so far.

- TDOT GREEN: The Japanese company Amuse Oneself Inc. developed a drone-mounted compact green laser scanner. The general concept and the sensor specifications are presented at the product's website together with exemplary uses cases for mapping coastal and river environments [50]. The scanner operates with a PRR of $60 \mathrm{kHz}$, a scan speed of $30 \mathrm{scans} / \mathrm{s}$, and provides up to 4 echoes per laser pulse. The large total Field of Fov (FoV) of $90^{\circ}$ is rather uncommon for bathymetric scanners as nominal laser incidence angles of $15-20^{\circ}$ are optimal for mapping bathymetry [1]. The laser output is automatically controlled depending on the flying altitude to ensure eye-safe operation $(<40 \mathrm{~m}$ : Class $1 ;>40 \mathrm{~m}$ : Class $3 \mathrm{R})$. The laser beam divergence of $0.3 \mathrm{mrad}$ results in a very small footprint diameter on the ground (e.g., $3 \mathrm{~cm}$ at a flying altitude of $100 \mathrm{~m}$ above ground level). However, no specific information is available on (i) the exact definition of the reported beam divergence and (ii) the actual laser power. [50] also reports data for validating sensor performance. Within these internal tests, the system achieved a maximum penetration of $9 \mathrm{~m}$ in clear seawater conditions and around $2 \mathrm{~m}$ in a more turbid river environment. However, no information on the actual turbidity is available and independent performance and accuracy evaluations are missing.

\subsection{Comparison and Accuracy Evaluation Studies}

As our contribution focuses on accuracy evaluation and performance assessment, we briefly list existing comparison studies related to optical remote sensing for mapping bathymetry in general, and ALB in particular. However, a comprehensive review is beyond the scope of this paper.

The authors of [51] provide a comparison of remote sensing methods for mapping bathymetry of shallow, clear water rivers. Their work mainly focuses on echo sounding and SfM-based techniques. Through-water photogrammetry and spectral depth approaches for water depth extraction based on UAV imagery are addressed in [52]. The authors state that a $1.5 \mathrm{~cm}$ DEM is achievable via the photogrammetric approach yielding an unbiased depth estimation with a standard deviation of $17 \mathrm{~cm}$ 
compared to RTK GNSS reference measurements, outperforming the spectral approach w.r.t. accuracy in their experiment at a shallow gravel-bed river.

In the area of bathymetric LiDAR, [53] introduces a comprehensive approach for the derivation of Total Vertical Uncertainty depending on flight mission and environmental parameters. In contrast, [54] summarize empirical quality control measures for the evaluation of ALB data and emphasize the necessity of collecting independent reference measurements for both bottom geometry (GNSS and/or Sonar) and water transparency. Actual geometric accuracy assessments of bathymetric LiDAR data captured from manned airborne platforms compared to independent reference data are reported in $[4,55-60]$. These studies discuss systematic biases as well as random errors. Depending on the used sensors (deep bathy, topo-bathy) and study areas (water depth, turbidity) the reported errors are in the $\mathrm{cm}$ - to dm-range compared to reference data obtained from sonar or GNSS. The systematic depth biases reported in $[55,56,59,60]$ are of special interest as they indicate insufficient compensation of refraction-induced effects. This topic will further be discussed in Section 6.

In the context of UAV-borne LiDAR hydro-mapping, [61] evaluated a bathymetric laser range finder. The instrument features a constant laser beam axis and provides section data with an along-track point spacing of around $1 \mathrm{~cm}$. The authors report a bias of $4 \mathrm{~cm}$ and a standard deviation of $3 \mathrm{~cm}$ comprising all involved error sources (sensor position and attitude, ranging, lever arms, boresight angles, etc.) compared to GNSS reference measurements of the gravel-bed river bottom. To the best of our knowledge, no accuracy assessments have been published for UAV-borne bathymetric laser scanners, which is the main focus of our contribution.

\section{Sensor Concept}

The RIEGL VQ-840-G is a fully integrated compact airborne laser scanner for combined topographic and bathymetric surveying. The instrument can be equipped with an integrated and factory-calibrated IMU/GNSS system and with an integrated industrial camera, thereby implementing a full airborne laser scanning system. The VQ-840-G LiDAR has a compact volume of $20.52 \mathrm{~L}$ with a weight of $12 \mathrm{~kg}$ and, thus, can be installed on various platforms including UAVs.

The laser scanner comprises a frequency-doubled IR laser, emitting pulses with about $1.5 \mathrm{~ns}$ pulse duration at a wavelength of $532 \mathrm{~nm}$ and at a PRR of $50-200 \mathrm{kHz}$. At the receiver side, the incoming optical echo signals are converted into an electrical signal, they are amplified and digitized at a digitization rate of close to $2 \mathrm{G}$ samples/s. The laser beam divergence can be selected between $1 \mathrm{mrad}$ and $6 \mathrm{mrad}$ in order to be able to maintain a constant energy density on the ground for different flying altitudes and therefore balancing eye-safe operation with spatial resolution. The receiver's iFOV (instantaneous Field of View) can be chosen between $3 \mathrm{mrad}$ and $18 \mathrm{mrad}$. For topographic measurements and very clear or shallow water, a smaller setting is suitable while for turbid water it is better to increase the receiver's iFOV in order to collect a larger amount of light scattered by the water body.

The VQ-840-G employs a Palmer scanner generating an elliptical scan pattern on the ground. The scan range is $\pm 20^{\circ}$ across and $\pm 14^{\circ}$ along the intended flight direction and consequently, the laser beam hits the water surface at an incidence angle with low variation. The scan speed can be set between 10-100 lines/s to generate an even point distribution in the center of the swath. Towards the edge of the swath, where the consecutive lines overlap, an extremely high point density with strongly overlapping footprints is produced.

The onboard distance measurement is based on time-of-flight measurement through online waveform processing of the digitized echo signal [62]. A real-time detection algorithm identifies potential targets within the stream of the digitized waveform and feeds the corresponding sampling values to the signal processing unit, which is capable of performing system response fitting (SRF) in real-time at a rate of up to $2.5 \mathrm{M}$ targets per second. These targets are represented by the basic attributes of range, amplitude, reflectance, and pulse shape deviation and are saved to the storage device, which can be the internal SSD a removable CFast $(C$ card, or an external data recorder via an optical data transmission cable. 
Besides being fed to target detection and online waveform processing, the digitized echo waveforms can also be stored on disc for subsequent off-line full waveform analysis. For every laser shot, sample blocks with a length of up to $75 \mathrm{~m}$ are stored unconditionally, i.e., without employing any target detection. This opens up a range of possibilities including pre-detection averaging (waveform stacking), variation of the target detection parameters or algorithm, and employing different sorts of full-waveform analysis. For the work presented here, offline SRF with modified target detection parameters was employed for optimized results. The depth performance of the instrument has been demonstrated to be in the range of 2 Secchi depths for single measurements, i.e., without waveform stacking.

Instead of or in addition to the internal camera, a high-resolution camera can be externally attached and triggered by the instrument. This option was chosen for the experiments in this study using a nadir looking Sony Alpha 7RM3. Figures 1 and 2 show conceptual drawings of the sensor and the general data acquisition concept, respectively. respectively. Table 1 summarizes the main sensor parameters.
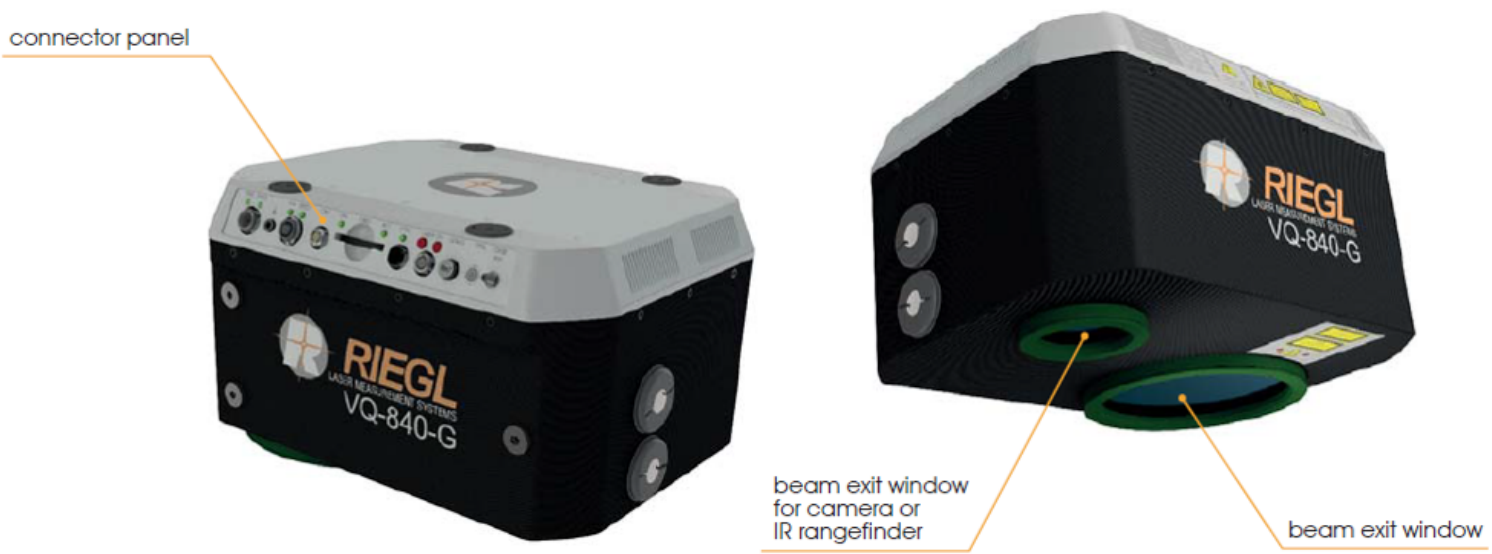

Figure 1. Computer Aided Design rendering of the VQ-840-G laser scanning system in basic configuration. The electrical and data interfaces are shown on the left hand side while the apertures for the green laser scanner and the camera at the bottom of the unit are shown on the right hand side.

Table 1. Sensor key specifications.

\begin{tabular}{ll}
\hline PRR & $50-200 \mathrm{kHz}$ \\
Scan rate & $10-100$ lines/s \\
Scan swath & \pm 20 deg across flight path, \pm 14 deg along flight path \\
Beam divergence & $1-6 \mathrm{mrad}$ \\
Receiver's iFOV & $3-18 \mathrm{mrad}$ \\
Size & $360 \mathrm{~mm} \times 285 \mathrm{~mm} \times 200 \mathrm{~mm}$ \\
Weight & $12 \mathrm{~kg}$ \\
Power consumption & $160 \mathrm{~W}$ \\
\hline
\end{tabular}




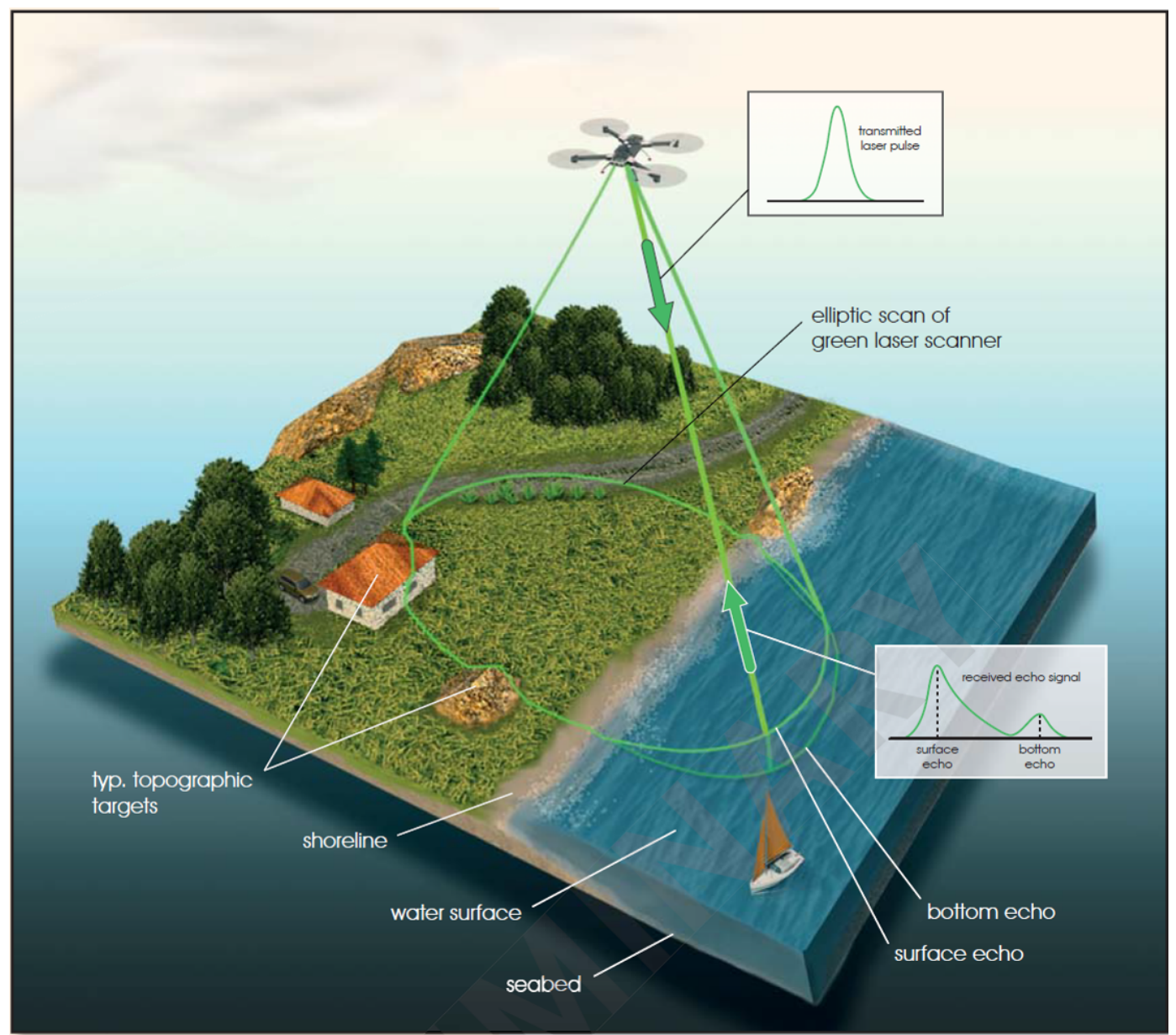

Figure 2. Visualisation of the VQ-840-G mounted on a drone in operation. The scan pattern on the ground is indicated by the green ellipse. The inserts show typical pulse shapes of the outgoing laser pulse and the echo return when measuring into the water.

\section{Materials And Methods}

In this Section, the study area is introduced in Section 4.1, the existing datasets are presented in Section 4.2, and the employed data processing methods are detailed in Section 4.3.

\subsection{Study Area}

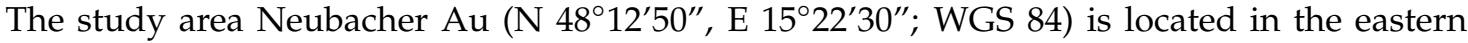
part of Austria at the tail-water of the pre-Alpine Pielach River, a right-side tributary of the Danube (cf. Figure 3). The study area is part of the conservation area Niederösterreichische Alpenvorlandflüsse (Area code: AT1219000) of the European Union's Natura2000 program. The river is classified as riffle-pool type [63] with a maximum depth of approximately $3 \mathrm{~m}$ and exhibits a pluvio-nival regime with expected discharge peaks during snowmelt in winter/spring and torrential rain in summer. Within the investigated reach, the mean annual discharge is about $7 \mathrm{~m}^{3} / \mathrm{s}$, the bed-load sediment is dominated by coarse gravel $(2-6.3 \mathrm{~cm})$, and the average gradient is about $0.4 \%$ [64]. The entire catchment area measures $590 \mathrm{~km}^{2}$ and the mean channel width is approximately $20 \mathrm{~m}$. Although the longitudinal continuum of the Pielach River is disrupted by weirs built for hydropower use and engineering measures, the river has retained some of its natural self-forming morphological characteristics like periodically inundated sidearms, dynamic gravel bars, large woody debris, small oxbows, etc., within the study area [65]. 


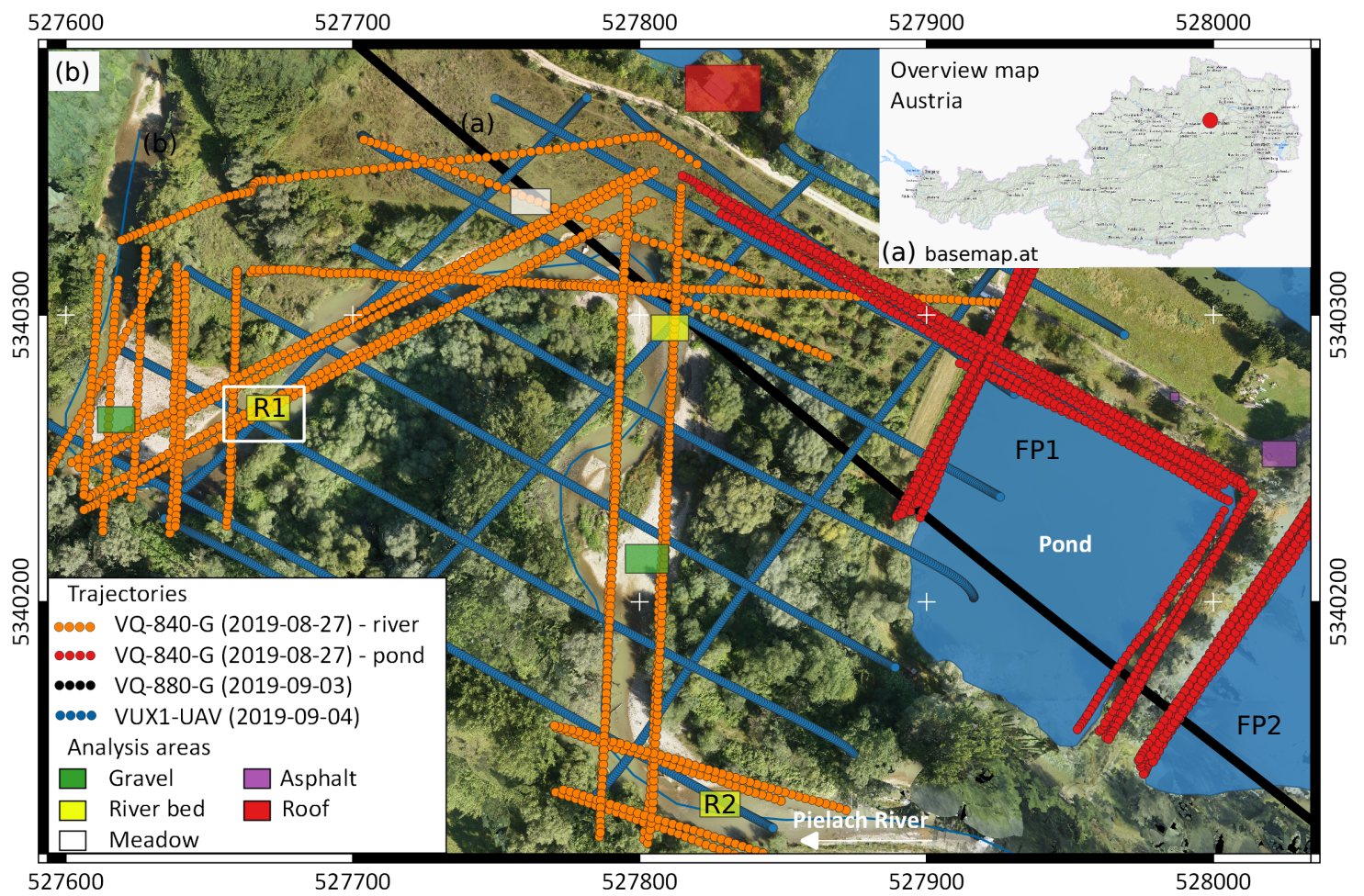

Figure 3. Study area Neubacher Au; (a) overview map of Austria with study area marked as a red circle; (b) orthophoto of the study area overlaid with flight trajectories (circles) and detailed analysis units (rectangles).

The floodplain to the north of the river features around a dozen groundwater supplied ponds (cf. right side of Figure 3). The bottom of the ponds is covered with a layer of mud, which is constantly stirred up by the fish population (e.g., Cyprinidae). This causes turbidity resulting in a Secchi depth of generally less than $2 \mathrm{~m}$. With an overall depth of around 5-6 $\mathrm{m}$, the ponds are ideal water bodies for testing the depth performance of bathymetric LiDAR sensors with a nominal depth performance of 1.5-2 SD.

Since 2013, the study area has been repeatedly captured with various topo-bathymetric laser scanners mounted on manned aircraft for monitoring river morphodynamics and instream habitats [4] as well as with UAV-borne topographic sensors for detailed analysis of the riparian area $[66,67]$. At the same site, first performance evaluations of a UAV-borne bathymetric laser range finder were carried out [61]. All these articles, as well as the cited literature therein, provide further details about the study area.

\subsection{Datasets}

In order to assess the accuracy potential and depth performance of the novel topo-bathymetric full-waveform laser scanner, two field campaigns were conducted on 28 August 2019, and 4 September 2019. The two dates are referred to as day 1 and day 2 in the following. On both days, the topo-bathymetric UAV-scanner was operated on a RiCOPTER-M octocopter platform and collected data of the ponds (flight lines marked with red dots in Figure 3) and of an approximately $650 \mathrm{~m}$ section of the Pielach River (orange dots).

For comparison and evaluation purposes, two additional LiDAR datasets were captured with the topographic UAV laser scanner VUX1-UAV mounted on a RiCOPTER UAV platform on day 2 and with the VQ-880-G sensor installed on a Diamond DA42 aircraft on 3 September 2019. The respective flight lines are plotted in Figure 3 (VUX1-UAV=blue dots, VQ-880-G=black dots). Both datasets served for cross-validation of the topo-bathymetric UAV-LiDAR data. 
Both UAV-based sensor systems operate RGB cameras along with the laser scanners. While the VQ-840-G carries a Sony $\alpha 7 R$ III (ILCE-7RM3) full-frame mirror-less interchangeable lens camera for capturing 42 MPix RGB nadir images, the VUX1-UAV is equipped with two oblique looking $24 \mathrm{MPix}$ Sony $\alpha 6000$ (ILCE-6000) APS-C format cameras matching the $230^{\circ}$-FoV of the VUX1 sensor. The RGB images of the latter served as basis for the orthophoto shown in Figure 3. The $\alpha 7 \mathrm{R}$ images, in turn, were used for evaluating the visual depth of the different water bodies during LiDAR data acquisition. Due to technical problems, $\alpha 7 \mathrm{R}$ images were only available for the pond flight lines on day 1 but not for the river flight lines.

The turbidity of the Pielach river depends on the flow velocity and discharge within the entire $590 \mathrm{~km}^{2}$ catchment area. Figure 4 a shows the annual mean daily discharge together with the lines for mean discharge $\left(\mathrm{MQ}=7.09 \mathrm{~m}^{3} \mathrm{~s}^{-1}\right)$ and the one-year flood peak $\left(\mathrm{HQ} 1=106.5 \mathrm{~m}^{3} \mathrm{~s}^{-1}\right)$, respectively. Discharges beyond the MQ-level only occurred during winter and spring, while summer 2019 was extremely dry with discharges around $2.5 \mathrm{~m}^{3} \mathrm{~s}^{-1}$ throughout the entire summer. In the days before the data acquisitions, typical summer thunderstorms entailed contamination with suspended debris (cf. Figure 4b) and, thus, a high turbidity level of the river water. While this is generally sub-optimal for laser bathymetry, these conditions also provided a chance to study the depth performance of the scanner and the accuracy implications within the available small range of water depths (Pielach river: $\approx 3 \mathrm{~m}$, ponds: $\approx 5-6 \mathrm{~m}$ ).

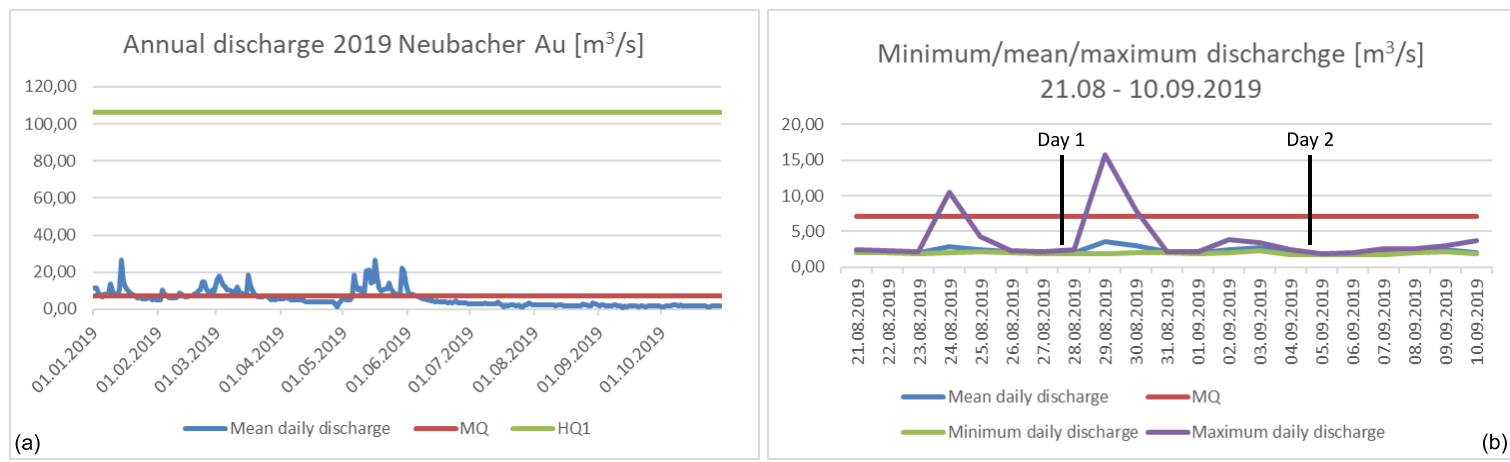

Figure 4. Discharge curves for study area Neubacher AU; (a) mean daily discharge for 2019 (blue) together with nominal mean discharge (MQ, red) and one-year flood peak (HQ1, green); (b) minimum, mean, and maximum daily discharge within the data acquisition period (flight dates marked with black ticks).

Table 2 summarizes the in-situ SD and turbidimeter measurements. Secchi depths were measured with a $30 \mathrm{~cm}$ black-and-white disk and for measurement of the concentration of suspended particles, a Hach 2100Q portable turbidimeter was employed. From both the SD- and turbidimeter values documented in Table 2, it can be stated that (i) pond FP2 tends to be more turbid than FP1; and (ii) turbidity was generally higher for day 2 compared to day 1 . This also relates to the higher discharge peak of $15.7 \mathrm{~m}^{3} \mathrm{~s}^{-1}$ caused by the thunderstorm event on 29 August before the second data acquisition day compared to the lower peak of $10.5 \mathrm{~m}^{3} \mathrm{~s}^{-1}$ resulting from the rain event on 24 August before day 1 (cf. Figure 4b).

Table 2. Secchi depth and turbidity measurements.

\begin{tabular}{cccc}
\hline Measuring Site & Day & Secchi Depth [m] & Turbidimeter [NTU] \\
\hline FP1 & 1 & 1.40 & 4.35 \\
FP2 & 1 & 1.00 & 4.52 \\
R1 & 1 & 1.10 & 7.90 \\
FP1 & 2 & 0.90 & 9.74 \\
R1 & 2 & 0.90 & 13.4 \\
R2 & 2 & 0.70 & - \\
\hline
\end{tabular}


During data acquisition, different scanner settings were tested w.r.t. their implications on depth performance, accuracy potential, and spatial resolution. As stated in Section 3, the bathymetric UAV-laser scanner features both a user-definable laser beam divergence and receiver iFoV. The prior is responsible for eye-safe operation and was set to $2 \mathrm{mrad}$ for all tests, while the PRR, flying altitude, and receiver $\mathrm{iFoV}$ were varied. Table 3 summarizes all parameter combinations. In total, the entire test procedure entailed six flights on day 1 and three flights on day 2 . The overall duration of each flight amounted to 13 minutes including data acquisition, take-off, initialization of the GNSS/IMU navigation system, and landing. The highest possible PRR of $200 \mathrm{kHz}$ could not be used due to the high power consumption of this scan mode.

Table 3. Flight mission parameters.

\begin{tabular}{|c|c|c|c|c|c|c|c|}
\hline Sensor & Area & Day & Altitude [m] & PRR [kHz] & Beam div. [mrad] & Rec. iFoV [mrad] & Camera \\
\hline VQ-840-G & Pond & 1 & 50 & 50 & 2.0 & 6.0 & $\alpha 7 \mathrm{R}$ \\
\hline$-1 \mid-$ & Pond & 1 & 65 & 50 & 2.0 & 6.0 & $\alpha 7 \mathrm{R}$ \\
\hline$-11-$ & Pond & 1 & 75 & 50 & 2.0 & 6.0 & $\alpha 7 \mathrm{R}$ \\
\hline$-11-$ & Pond & 1 & 55 & 100 & 2.0 & 6.0 & $\alpha 7 \mathrm{R}$ \\
\hline$-11-$ & Pond & 1 & 75 & 100 & 2.0 & 6.0 & $\alpha 7 \mathrm{R}$ \\
\hline$-1 \mid-$ & Pond & 1 & 50 & 50 & 2.0 & 18.0 & $\alpha 7 \mathrm{R}$ \\
\hline$-1-$ & Pond & 1 & 75 & 50 & 2.0 & 18.0 & $\alpha 7 \mathrm{R}$ \\
\hline VQ-840-G & River & 1 & 50 & 50 & 2.0 & 6.0 & - \\
\hline$-11-$ & River & 1 & 75 & 50 & 2.0 & 6.0 & - \\
\hline VQ-840-G & River & 2 & 55 & 50 & 2.0 & 18.0 & $\alpha 7 \mathrm{R}$ \\
\hline$-11-$ & River & 2 & 75 & 50 & 2.0 & 18.0 & $\alpha 7 \mathrm{R}$ \\
\hline VUX1-UAV & River & 2 & 75 & 550 & 0.5 & 4.5 & $\alpha 600$ \\
\hline VQ-840-G & River & 2 & 650 & 550 & 1.3 & 7.0 & - \\
\hline
\end{tabular}

For validation of the scan data, several reference targets were positioned in the pond and river. To evaluate the effective penetration depth of the bathymetric UAV-scanner, four white-colored metal plates of $1 \times 1 \mathrm{~m}^{2}$ size were lowered into pond FP1 on day 1. Each plate was floating in an individual constant water depth, with depths varying from $1.1 \mathrm{~m}$ to $3.1 \mathrm{~m}$, corresponding to $0.8-2.2 \mathrm{SD}$. The floating of the plates was realized by attaching ropes to the four corners of each plate and mounting styrofoam buoyancy bodies to the other end of the ropes. Figure 5 shows the four plates in one of the $\alpha 7 \mathrm{R}$ images during data acquisition on day 1.

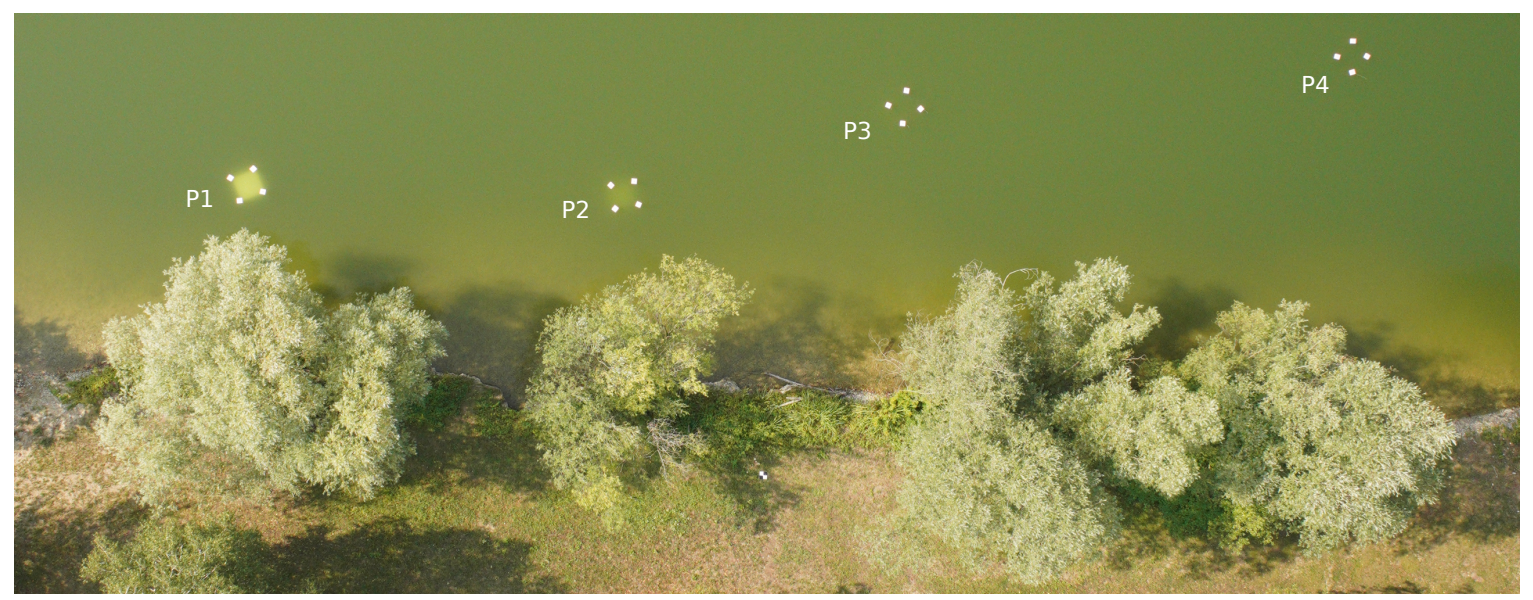

Figure 5. The $1 \times 1 \mathrm{~m}^{2}$ plates (P1-P4) floating in pond FP1 for evaluation of depth performance; camera: $\alpha 7 \mathrm{R}$; acquisition: day 1; depth of plate from left to right: $1.1 \mathrm{~m}, 1.9 \mathrm{~m}, 2.6 \mathrm{~m}, 3.1 \mathrm{~m}$. 
To assess the bathymetric accuracy, an array of three parallel profiles with 6-7 checkerboard targets (i.e., black-and-white disks of $20 \mathrm{~cm}$ or $30 \mathrm{~cm}$ diameter, respectively) were anchored in the gravel riverbed and measured with a Leica TS16 total station on day 1 . The approximate position of the reference target field is marked as R1 in Figure 3. The 19 reference targets exhibited a minimum, mean, and maximum depth of $0.33 \mathrm{~m}, 1.44 \mathrm{~m}$, and $2.15 \mathrm{~m}$, respectively. Snorkeling was employed for fixing the checkerboard targets in the riverbed as well as positioning the measurement pole in the target's center hole. This was especially necessary for all targets featuring a depth of more than $1 \mathrm{~m}$. As a guide for both installation and measurement, a rope was fixed on both sides of the riverbank. The photographs in Figure $6 c-$ e illustrate the setup of the reference target field.

Furthermore, Figure 6a shows one of the black-and-white checkerboard targets used as ground control points (GCP) for absolute orientation of the image block as well as the laser scans. In total, 25 of theses quadratic targets (edge length: $30 \mathrm{~cm}$ ) were distributed within the entire study area and measured with a Spectra Precision SP80 GNSS receiver in real-time kinematic (RTK) mode based on correction data obtained from the local GNSS service provider EPOSA. The GCPs feature a total horizontal and total vertical uncertainty, respectively, of less than $2 \mathrm{~cm}(1 \sigma)$. While GCPs are the first choice for absolute orientation of an image block, laser scanning requires planar control patches. Two A-shaped saddle roofs composed of wooden formwork panels, one on each side of the river in close vicinity to the reference target field, served as the basis for the absolute orientation of the laser flight block (cf. Figure 6d,e). The data captured on day 2 were only used for orthophoto generation and cross-validation on dry land due to the very high turbidity on this day. The topo-bathymetric LiDAR data of day 1 , in turn, serve as a basis of all subsequently described data processing steps and the presented results.
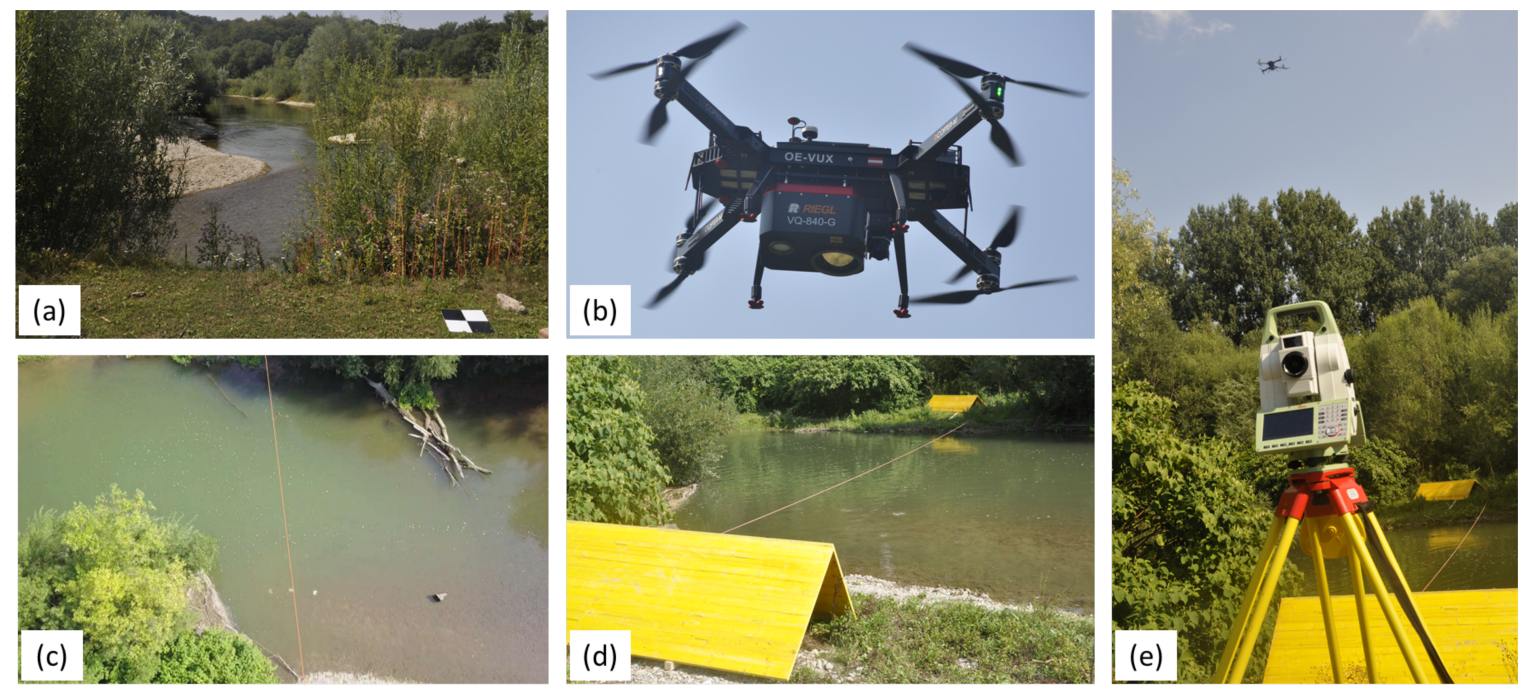

Figure 6. Photo documentation of data acquisition on 27 August (day 1); (a) Pielach river with quadratic black-and-white checkerboard ground control point target in the foreground; (b) topo-bathymetric UAV laser scanner RIEGL VQ-840-G during data capture; (c) UAV-image of field of submerged circular black-and-white checkerboard targets aligned with rope fixed between both riverbanks; (d) terrestrial photo of reference target field, most of the targets are not visible with the naked eye due to the limited Secchi depth of $1.1 \mathrm{~m}$, yellow wooden plates in fore- and background: saddle roof control patches for absolute orientation of laser scans; (e) total station Leica TS16 in front of reference field and control patches. 


\subsection{Data Processing Methods}

In the following, the general workflow including preprocessing, refraction correction of the raw LiDAR point clouds, assessment of accuracy and spatial resolution, and evaluation of depth performance is summarized. For most of the processing steps, the scientific laser scanning software OPALS [68] was employed.

\subsubsection{Preprocessing}

Data preprocessing comprised the following steps:

- $\quad$ Post-processing of raw GNSS and total station data and calculation of 3D coordinates of ground control points and checkpoints using Leica software

- Aero-triangulation of all captured images and derivation of digital orthophotos using Pix4DMapper [20]

- $\quad$ Post-processing of flight trajectory data and derivation of a Smoothed Best Estimate Trajectory (SBET) [69] using observations from the installed permanent reference station

- Direct georeferencing of the laser echoes originating from online waveform processing using the manufacturer's software RiPROCESS

- $\quad$ Geometric calibration of flight block via strip adjustment [70,71]. The ICP-based calibration procedure included estimation of mounting parameters (boresight angles, lever arm) as well as additional trajectory corrections per strip. For each strip, a constant offset (X, Y, Z, roll, pitch, yaw) was estimated to further improve the strip fitting precision. Consideration of the terrestrially measured ground control points and saddle roof models (cf. Figure 6a,d) in the strip adjustment ensured optimal absolute orientation of the flight block and consistency to the (submerged) checkpoints.

- Quality check of the resulting 3D point cloud, calculation of strip-wise DEMs, and derivation of pairwise DEM of Difference models including statistical analysis of the resulting strip height differences in smooth areas [72]

- Derivation of strip-wise water surface models. First, approximate water levels were derived interactively with the editing tool qpals (i.e., QGIS plugin for OPALS software) based on the approach described in [73]. This initial water surface model served as the basis for selecting potential water surface points as seed points for region growing segmentation. In the last step, all classified water surface points were used to derive the final strip-wise water surface model as a regular $50 \mathrm{~cm}$ grid using moving least squares interpolation. The resulting water surface models capture the low-frequency contributions of the wave-induced water surface shape while smoothing out higher frequency parts.

- Refraction correction of the raw laser echoes according to the Snell's law [74]. Based on a recent publication [75], a refraction coefficients of $n=1.33$ was employed for beam deflection whereas coefficients of $n>=1.36$ were used for round-trip-time correction.

\subsubsection{Evaluation}

1. Precision: Assessment of precision comprised evaluation of measurement noise and geometric consistency of overlapping strips.

- Measurement noise: Assessment of the sensor's noise level was carried out at smooth surfaces (e.g., asphalt) within the individual strips by estimating a best-fitting plane for each point of an appropriate surface patch via least-squares adjustment based on the k nearest neighbor points $(\mathrm{k}=12)$ within a maximum search radius of $50 \mathrm{~cm}$. For surfaces with known planar geometry, the residuals (i.e., point-to-plane normal distances) provide an estimate of the sensor's ranging precision (cf. Figure 7a). 
- Strip fitting precision: The height deviations in smooth parts (cf. Figure $7 \mathrm{~b}$ ) of overlapping flight strips provide an estimate of the overall quality of the sensor system including GNSS/IMU navigation device, LiDAR unit, and scanning mechanism. First, strip-wise DEMs were interpolated using moving least squares interpolation, and subsequently, the height discrepancies in smooth surface parts were visualized in color-coded maps and statistically analyzed (histograms, standard statistics). For the quantification of bias and dispersion, robust statistics (bias: median, dispersion: $\sigma_{M A D}=$ Median of Absolute Differences) are employed. Separate analysis of dry land and submerged areas enable a distinction between effects stemming from sensor calibration and flight block orientation (land) and effects connected to water surface estimation and refraction correction.

2. Accuracy: estimation of absolute accuracy relies on a comparison of the laser derived point cloud with the independently captured reference points measured as point-to-plane distances (cf. Figure $7 \mathrm{c}$ ). For each reference point, the k-nearest laser points $(k=8)$ within a maximum search radius of $15 \mathrm{~cm}$ served as input for fitting a tilted plane via least-squares adjustment. The normal distance between the reference point and the plane constitutes an objective measure of overall accuracy as it comprises all possible error sources.

3. Depth performance: Quantifying the achieved maximum depth penetration is accomplished via a comparison of the known depths of the metal plates with the depths derived from the corresponding laser returns. In case the plate was discernible, the points in the center of the plate were selected and served as the basis for the median-based estimation of the plate's representative height. The process was repeated for all strips containing laser echoes of the plate also considering the individual sensor settings of the respective strip (beam divergence, $\mathrm{iFoV}$, flying altitude).

4. Spatial resolution: the theoretical resolution derived from the flight mission and sensor parameters (beam divergence, pulse repetition and scan rate, flying altitude and speed), is confronted with the actual resolution derived from the captured laser points. The studied objects are a rope spanned across the river and the right-angle shaped wooden plates (cf. Figure 6d). For the linear feature, all neighboring laser points are projected to the rope axis allowing analysis of the lateral distances (cf. Figure 7d) and for the roof-shaped feature, the shape of the point cloud is analyzed in the vicinity of the crest line, where the point cloud shows substantial rounding of the sharp edge.

(a)

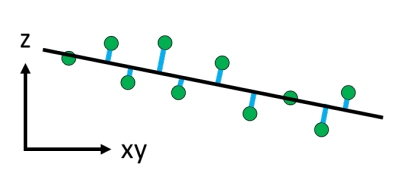

(b)

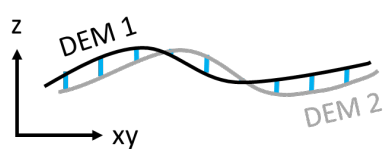

(c)

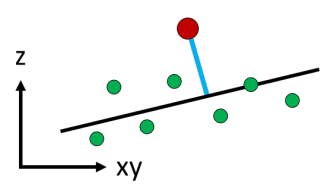

(d)

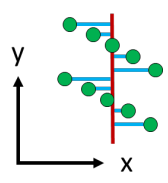

- Laser point $\quad$ Reference point Reference line $\quad$ Deviation measure

Figure 7. Conceptual sketch of employed deviation measures (blue lines). (a) measurement noise; (b) strip fitting precision; (c) accuracy w.r.t. reference points; (d) spatial resolution.

\section{Results}

In this section, we present the quality evaluation results separated into precision (Section 5.1), accuracy (Section 5.2), depth performance (Section 5.3), and spatial resolution (Section 5.4).

\subsection{Precision}

\subsubsection{Measurement Noise}

Figure 8 shows five selected surface patches (asphalt: A1, A2, gravel: G1, G2, and meadow: M1). For each patch we provide the orthophoto and DEM (color-coded height map superimposed with $1 \mathrm{~cm}$ contour lines) in the first two rows. The last row exhibits a plot of the local interpolation error $\left(\sigma_{0}\right)$. 
In case of a sufficiently planar surface, $\sigma_{0}$ quantifies the measurement noise (reproducibility). This is especially the case for A1. All other patches exhibit small scale topographic variations (gravel, G1 and G1) or undulations due to grass vegetation (A2, M1).

A1

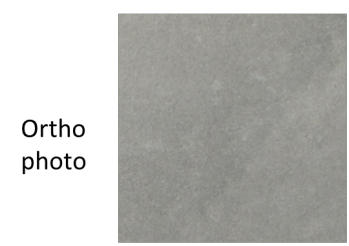

DEM

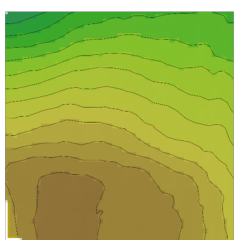

$\sigma_{0}$

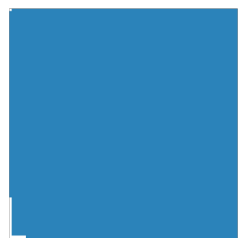

A2
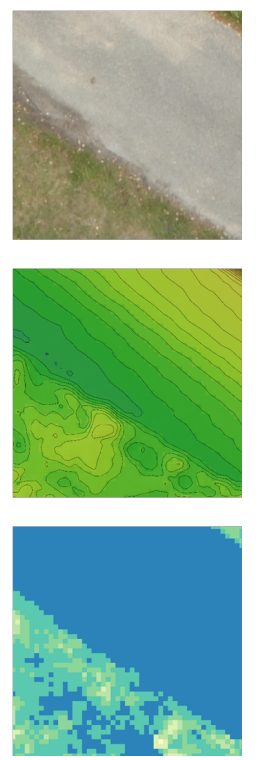

G1
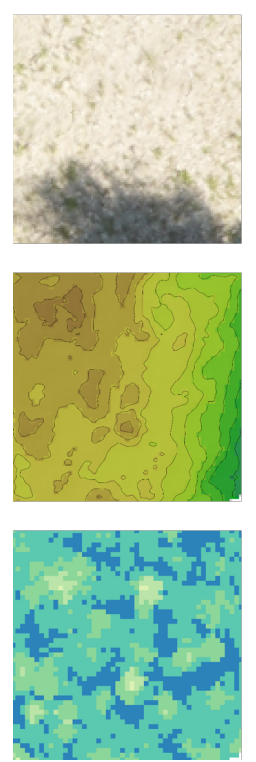

G2
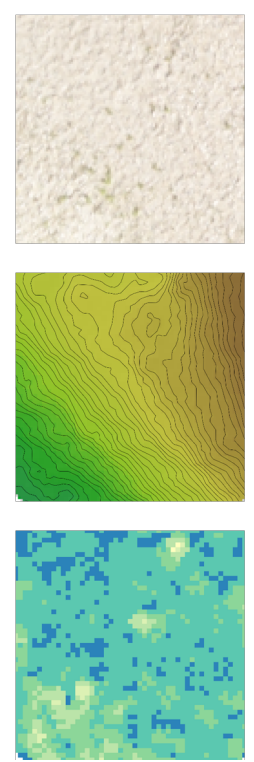

M1
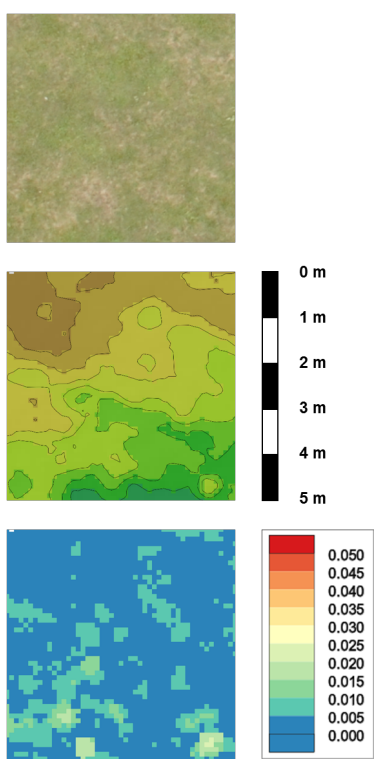

Figure 8. Visualization of measurement noise for selected $5 \times 5 \mathrm{~m}^{2}$ surface patches; A1: asphalt, A2: asphalt and grass, G1/G2: gravel bank, M1: meadow; first row: digital orthophoto, second row: color coded height map superimposed with $1 \mathrm{~cm}$ contour lines, third row: color coded map of local surface roughness (i.e., $\sigma_{0}[\mathrm{~m}]$ ).

Table 4 summarizes the quantitative results. For the asphalt dominated patches Table 4 also documents the noise level variations depending on the mission parameters (flying altitude, iFoV). For A1, $\sigma_{0}$ is below $2 \mathrm{~mm}$ for a narrow iFoV of 6 mrad and slightly higher $(3.5 \mathrm{~mm})$ for the wider iFoV of $18 \mathrm{mrad}$. For the mixed asphalt/grass patch A2, increasing the flying altitude from $50 \mathrm{~m}$ to $70 \mathrm{~m}$ does not effect the precision (mean: $\approx 4 \mathrm{~mm}$, median: $\approx 3 \mathrm{~mm}$ ). In both cases, the higher mean value reflects the higher variations within the grass vegetation, while the more robust median can be seen as representative for the dominant asphalt area. For all other patches, the micro-relief leads to increased $\sigma_{0}$ values, which are in the range of $1 \mathrm{~cm}$ for the gravel patches (G1, G2) and around $5 \mathrm{~mm}$ for the meadow patch M1. All reported values are below $15 \mathrm{~mm}$, the precision value reported in the sensor's spec sheet [9].

Table 4. Evaluation of measurement noise reported as local $\sigma_{0}$ (mean, median, and interquartile range (IQR)).

\begin{tabular}{cccccc}
\hline Patch & Altitude $[\mathrm{m}]$ & iFoV [mrad] & Mean $[\mathrm{mm}]$ & Median $[\mathbf{m m}]$ & IQR [mm] \\
\hline A1 & 65 & 6 & 1.9 & 1.8 & 0.7 \\
A1 & 50 & 18 & 3.4 & 3.3 & 1.4 \\
A2 & 50 & 6 & 4.4 & 2.3 & 4.7 \\
A2 & 50 & 18 & 4.2 & 3.1 & 3.6 \\
A2 & 70 & 18 & 3.9 & 2.9 & 3.1 \\
G1 & 50 & 6 & 7.6 & 6.9 & 4.5 \\
G2 & 50 & 6 & 8.2 & 7.4 & 3.9 \\
M1 & 50 & 6 & 4.6 & 3.2 & 2.1 \\
\hline
\end{tabular}




\subsubsection{Strip Fitting Precision}

Figure 9 shows a color-coded map of strip height differences in smooth surface areas on top of a DSM map of the entire UAV-LiDAR flight block (color-coded elevation map superimposed with shaded relief map). The dominant white color tones of the strip differences indicate deviations of less than $2 \mathrm{~cm}$ and confirm the good fitting precision of the flight strips. The histogram of the strip height differences plotted in the lower-left corner of Figure 9 exhibits a symmetric shape. The distribution is unbiased (mean: $1 \mathrm{~mm}$, median: $0 \mathrm{~mm})$ with a dispersion of $9 \mathrm{~mm}\left(\sigma_{M A D}\right)$. Occasional strip differences in vegetated areas, which have passed the automatic smoothness filter, are responsible for the comparably high standard deviation of $10 \mathrm{~cm} .96 \%$ of the strip height differences are within a range of $-24 \mathrm{~mm}$ to $+25 \mathrm{~mm}$, which further underlines the fidelity of the entire sensor system including navigation device, laser ranging unit, and scanner.

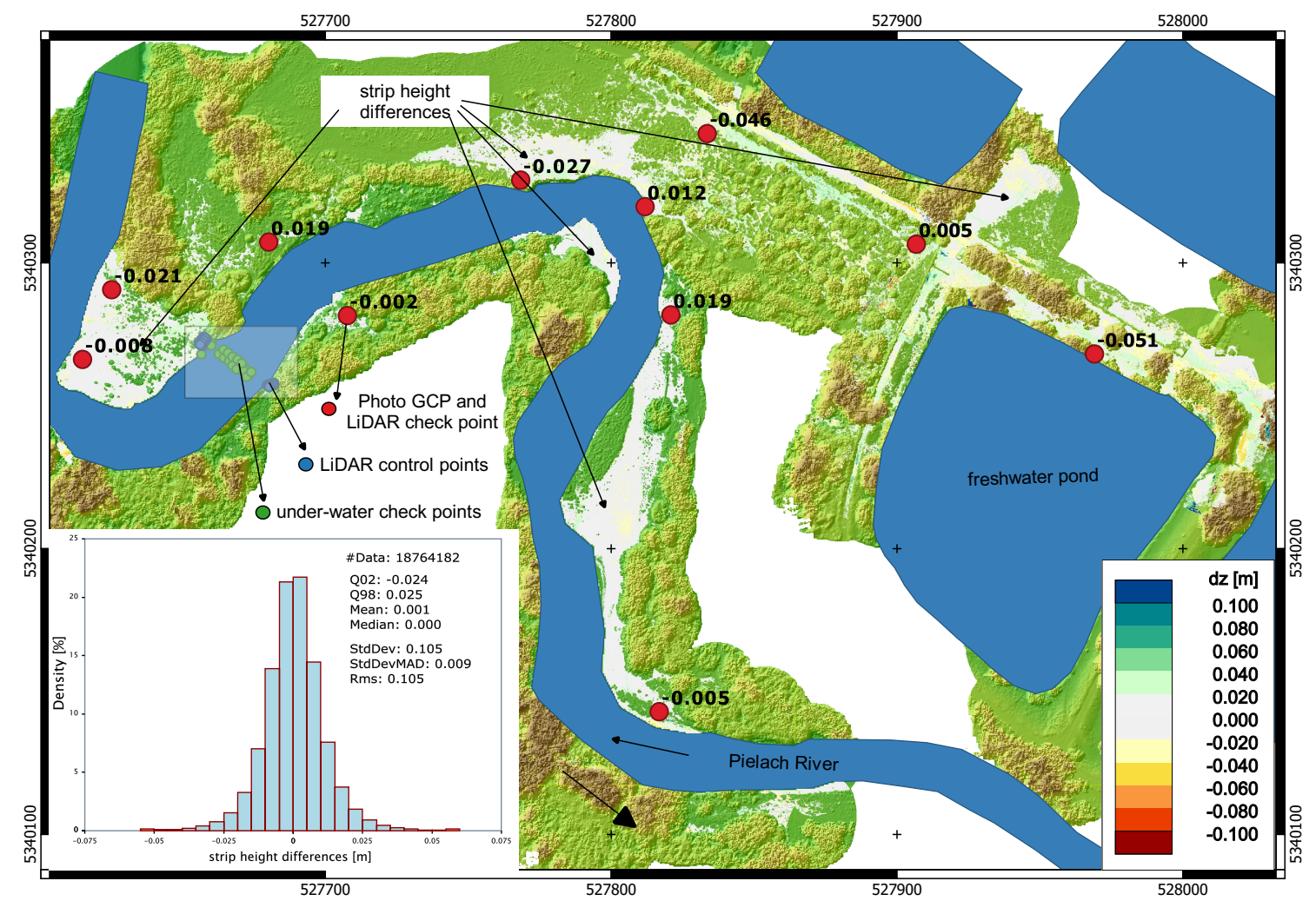

Figure 9. Color coded mosaic of strip height differences, background: LiDAR DSM (color coded elevation map superimposed with shaded relief map), lower left: histogram of height differences in smooth surface areas, lower right: color bar for strip differences.

\subsection{Accuracy Assessment}

The absolute accuracy, measured as signed point-to-plane distances between terrestrially measured reference points and LiDAR-derived planes are plotted in Figure 9 (labeled red dots) and Figure 10 for land and underwater, respectively.

On the land side, the deviations are mainly below $3 \mathrm{~cm}$, with only two checkpoints at the western end of the flight block exhibiting deviations of $\approx 5 \mathrm{~cm}$. The poorer absolute fitting accuracy in this part of the block is due to the unavailability of appropriate laser control patches in this area of the block, where absolute orientation was of minor concern for the conducted evaluation. Control patches (wooden saddle roof formwork constructions) were located in the vicinity of the river section featuring the submerged reference targets (cf. Figure $6 \mathrm{c}-\mathrm{e}$ ). In this area utmost accuracy of the absolute block orientation was crucial, and the deviations in this region are $2 \mathrm{~cm}$ or better. Table 5 summarize the deviations on dry land for selected reference points on the saddle roof shaped control patches 
(CP, cf. blue dots in Figure 9) and on the water-land-boundary (WLB, cf. black dots in Figure 9). The deviations are generally below $1 \mathrm{~cm}$ (cf. points 1001-1020, 2001-2010, 108-110) and only the points on the ridge of the control patches (1022-1024, 2010-2012) exhibit larger, systematically negative deviations of more than $3 \mathrm{~cm}$. This will be further discussed in Sections 5.4 and 6 .

Table 5. Accuracy assessment for reference targets on land; selected point-to-plane distances [m] between reference points and LiDAR derived planes.

\begin{tabular}{ccrccrcrr}
\hline ID & Area & Dev. & ID & Area & Dev. & ID & Area & Dev. \\
\hline 1001 & $\mathrm{CP}(\mathrm{W})$ & -0.006 & 2001 & $\mathrm{CP}(\mathrm{E})$ & 0.013 & 108 & WLB & -0.005 \\
1005 & $\mathrm{CP}(\mathrm{W})$ & -0.007 & 2003 & $\mathrm{CP}(\mathrm{E})$ & 0.001 & 109 & WLB & -0.008 \\
1010 & $\mathrm{CP}(\mathrm{W})$ & 0.008 & 2005 & $\mathrm{CP}(\mathrm{E})$ & -0.006 & 110 & WLB & 0.006 \\
1016 & $\mathrm{CP}(\mathrm{W})$ & -0.004 & 2008 & $\mathrm{CP}(\mathrm{E})$ & -0.002 & & & \\
1020 & $\mathrm{CP}(\mathrm{W})$ & -0.006 & 2010 & $\mathrm{CP}(\mathrm{E})$ & -0.035 & & & \\
1021 & $\mathrm{CP}(\mathrm{W})$ & -0.031 & 2011 & $\mathrm{CP}(\mathrm{E})$ & -0.045 & & & \\
1022 & $\mathrm{CP}(\mathrm{W})$ & -0.034 & 2012 & $\mathrm{CP}(\mathrm{E})$ & -0.079 & & & \\
1023 & $\mathrm{CP}(\mathrm{W})$ & -0.033 & 2013 & $\mathrm{CP}(\mathrm{E})$ & 0.003 & & & \\
1024 & $\mathrm{CP}(\mathrm{W})$ & -0.036 & 2014 & $\mathrm{CP}(\mathrm{E})$ & -0.001 & & & \\
\hline
\end{tabular}

Figure 10 shows the results of the bathymetric accuracy assessment for all 20 submerged reference targets. The upper left plot shows the locations of the reference targets, arranged in three cross-sections, together with the point labels of the middle section, for which the deviations are presented numerically in Table 6 together with the respective water depth. For refraction correction of the raw laser echoes, we strictly used a refractive index of $n=1.33$ for beam deflection (i.e., angular component). For run-time correction, we varied the coefficient from $n=1.33$ to $n=1.36$ according to literature $[75,76]$ and also beyond that till $n=1.42$. Table 6 shows that the use of standard refraction coefficients $(1.33,1.36)$ leads to a systematic, depth-dependent, negative bias indicated by the red color tones. The respective columns in Table 6 also clearly show the depth-dependent increase of the deviations reaching $7.8 \mathrm{~cm}$ for the deepest point 206 (water depth $=2.1 \mathrm{~m}$ ) for refractive index of 1.36. Due to this unexpected systematic effect, we first double-checked the accuracy of the water surface, but did not find any evidence that the modeled water surface model is responsible for the bias (cf. deviations water-land-boundary points in Table 5 and the cross-sectional plot in Figure 11). In addition, we performed refraction correction with different software tools (RiPROCESS, OPALS) leading to consistent results. We, therefore, performed tests with refraction coefficients beyond $n=1.36$ and found that the bias entirely disappears for $n=1.42$. This can be seen from the white color tones of the respective plots in Figure 10 as well as from the underlined values in Table 6.
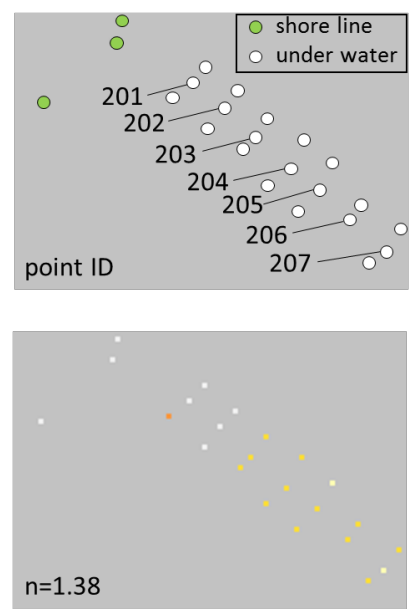
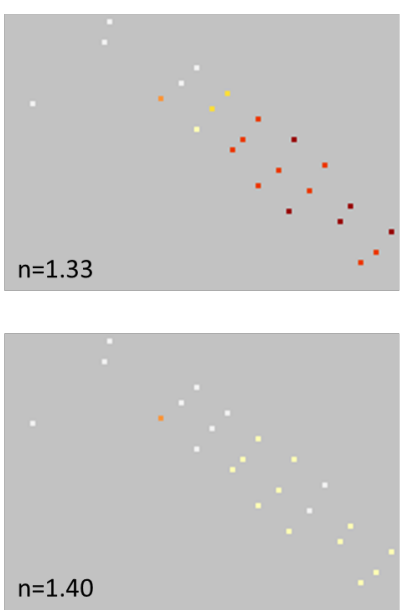
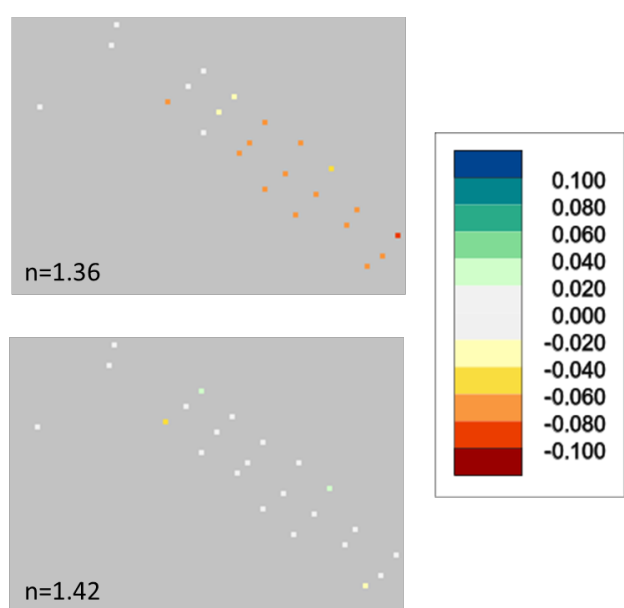

$\mathrm{n}=1.42$

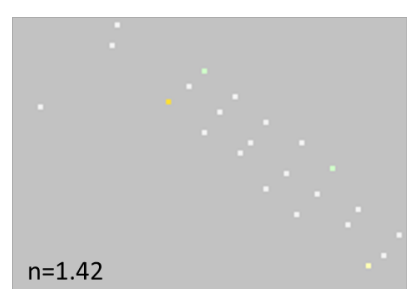

Figure 10. Color coded point-to-plane distances $[\mathrm{m}]$ between check points and LiDAR derived planes, run-time correction based on refraction coefficients ranging from $n=1.33$ to $n=1.42$. 
Table 6. Accuracy assessment for underwater reference targets; selected point-to-plane distances $[\mathrm{m}]$ between reference points and LiDAR derived planes using different refraction coefficients for run-time correction.

\begin{tabular}{rlrrrrr}
\hline ID & Depth & $\mathbf{n = 1 . 3 3}$ & $\mathbf{n = 1 . 3 6}$ & $\mathbf{n = 1 . 3 8}$ & $\mathbf{n}=\mathbf{1 . 4 0}$ & $\mathbf{n}=\mathbf{1 . 4 2}$ \\
\hline 201 & 0.395 & -0.006 & $\mathbf{0 . 0 0 4}$ & 0.009 & 0.014 & $\mathbf{0 . 0 1 6}$ \\
202 & 0.934 & -0.048 & $-\mathbf{0 . 0 2 7}$ & -0.016 & -0.001 & $\mathbf{0 . 0 1 1}$ \\
203 & 1.260 & -0.088 & $-\mathbf{0 . 0 6 1}$ & -0.043 & -0.026 & $-\mathbf{0 . 0 0 9}$ \\
204 & 1.425 & -0.094 & $-\mathbf{0 . 0 6 6}$ & -0.045 & -0.026 & $-\mathbf{0 . 0 0 6}$ \\
205 & 1.881 & -0.098 & $-\mathbf{0 . 0 6 9}$ & -0.041 & -0.019 & $\underline{\mathbf{0 . 0 0 0}}$ \\
206 & 2.097 & -0.123 & $-\mathbf{0 . 0 7 8}$ & -0.050 & -0.029 & $\mathbf{0 . 0 0 1}$ \\
207 & 1.443 & -0.094 & $-\mathbf{0 . 0 6 3}$ & -0.039 & -0.022 & $-\mathbf{0 . 0 0 6}$ \\
\hline
\end{tabular}

Figure 11 shows a vertical section of the refraction corrected LiDAR point cloud $(n=1.36)$ colored by signal amplitude overlaid with (i) the reference points (magenta) and (ii) the modelled water surface (black). The saddle roof on the right (i.e., western) embankment shows very good agreement with the reference points whereas the submerged reference targets lie systematically above the LiDAR point cloud of the river bottom.

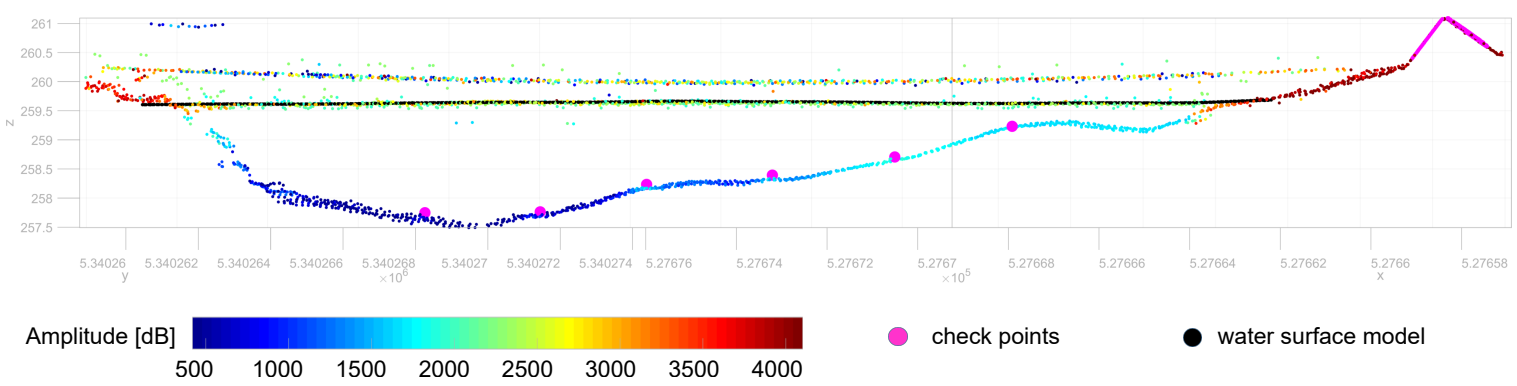

Figure 11. Vertical section of refraction corrected 3D point cloud $(n=1.36)$ of strip 105334 colored by signal amplitude; larger magenta dots: checkpoints, black: modelled water surface.

\subsection{Depth Performance}

To evaluate the sensor's depth performance, four white metal plates were lowered into pond FP1 at the eastern border of the flight block (cf. Figure 5) in depths of 1.1-3.1 m corresponding to 0.8-2.2 SD. The plates were captured multiple times with different sensor settings (PRR, altitude, iFoV). Figure 12 depicts the 3D point clouds of two selected strips $(063116,093054)$, both flown $50 \mathrm{~m}$ above ground level with a PRR of $50 \mathrm{kHz}$, but with a different iFoV of $6 \mathrm{mrad}$ and $18 \mathrm{mrad}$, respectively. Figure 12 reveals that the wider iFoV generally delivers more points on the detectable plates P1-P3 and the plates appear larger than the nominal size of $1 \mathrm{~m}^{2}$. The signal amplitude is higher for the wider $18 \mathrm{mrad} \mathrm{iFoV}$, indicated by the more reddish color tones, as more backscattered laser light reaches the detector. 


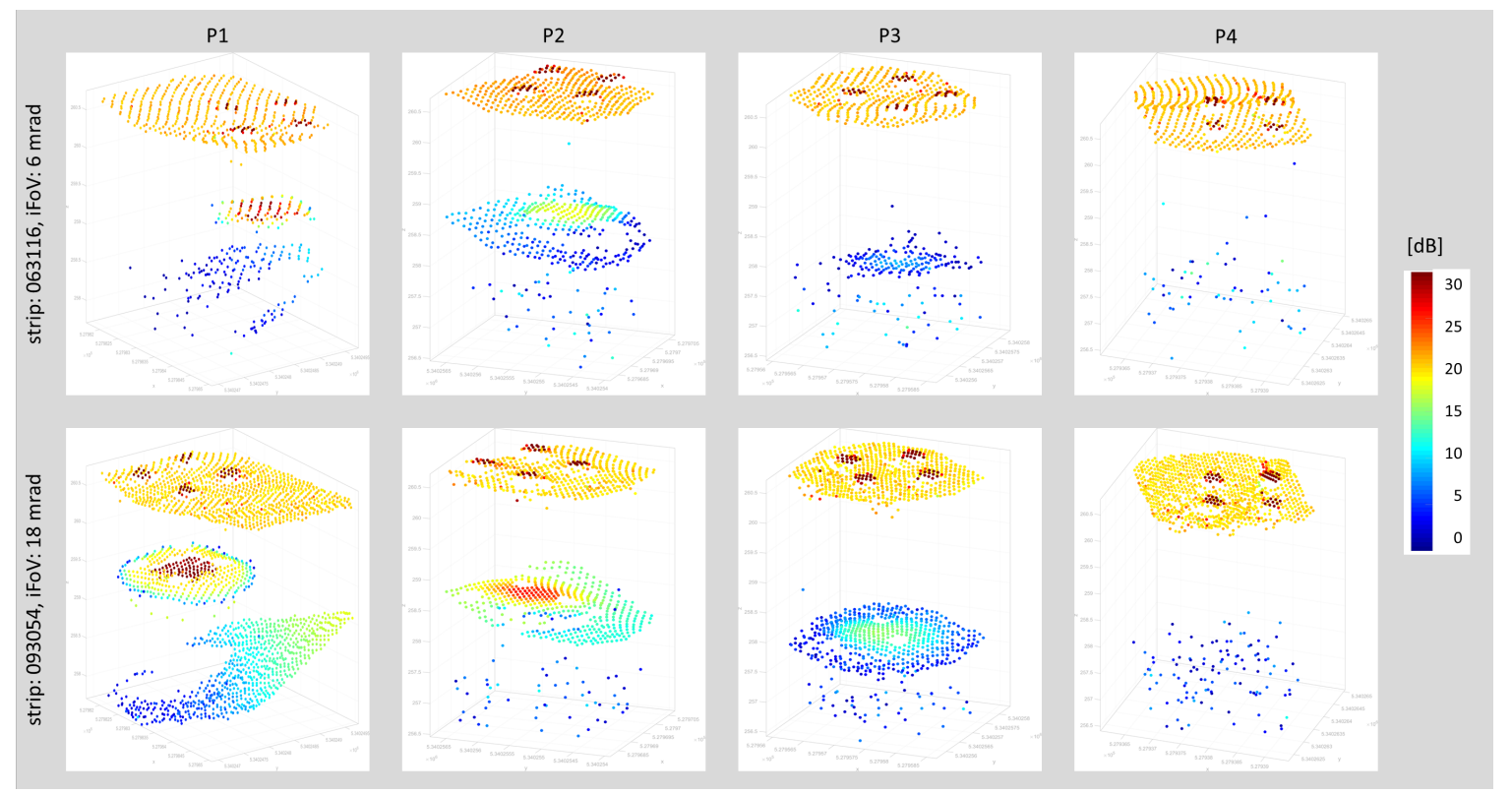

Figure 12. Perspective view of 3D point points of lowered metal plates P1-P4 colored by signal amplitude [dB]. upper row: strip 063116, iFoV: 6 mrad, lower row: strip 093054, iFoV: 18 mrad.

For the same strips, Table 7 provides a quantitative summary. Table 7 documents that plates P1-P3 could be detected in the point clouds, but not $\mathrm{P} 4$ at a depth of $3.11 \mathrm{~m}$ or $2.2 \mathrm{SD}$, respectively. This holds for the strip flown with a $6 \mathrm{mrad}$ iFoV as well as for the strip with the wider $18 \mathrm{mrad}$ iFoV. As expected, the signal amplitude level of the $18 \mathrm{mrad} \mathrm{iFoV}$ is generally higher for all plates, and at $\mathrm{P} 3$ the receiver still measures $14.5 \mathrm{~dB}$. This, however, was not enough to identify P4 located just beyond the $2 \mathrm{SD}$ limit. The relative depth of $\mathrm{P} 3$ amounts to $1.94 \mathrm{SD}$, thus, slightly below the sensor specification of $2 \mathrm{SD}$. Furthermore, the nominal-actual depth comparison reveals the same systematic depth overestimation as already reported in Section 5.2.

Table 7. Depth performance assessment.

\begin{tabular}{ccccccccc}
\hline Plate & Strip & iFoV & $\begin{array}{c}\text { Altitude } \\
{[\mathbf{m}]}\end{array}$ & $\begin{array}{c}\text { Nominal Depth } \\
{[\mathbf{m}]}\end{array}$ & $\begin{array}{c}\text { Actual Depth } \\
{[\mathbf{m}]}\end{array}$ & $\begin{array}{c}\text { Deviation } \\
{[\mathrm{m}]}\end{array}$ & $\begin{array}{c}\text { rel. Depth } \\
{[\text { [SD] }}\end{array}$ & $\begin{array}{c}\text { Amplitude } \\
\text { [dB] }\end{array}$ \\
\hline P1 & 063116 & 6 & 50 & 1.16 & $1.18 \pm 0.01$ & 0.02 & 0.84 & 26.8 \\
P2 & 063116 & 6 & 50 & 1.99 & $2.03 \pm 0.02$ & 0.04 & 1.45 & 17.6 \\
P3 & 063116 & 6 & 50 & 2.64 & $2.71 \pm 0.01$ & 0.07 & 1.94 & 7.8 \\
P4 & 063116 & 6 & 50 & 3.11 & - & - & - & - \\
\hline P1 & 093054 & 18 & 50 & 1.16 & $1.18 \pm 0.01$ & 0.01 & 0.84 & 29.7 \\
P2 & 093054 & 18 & 50 & 1.99 & $2.03 \pm 0.02$ & 0.04 & 1.45 & 22.7 \\
P3 & 093054 & 18 & 50 & 2.64 & $2.74 \pm 0.01$ & 0.10 & 1.94 & 14.5 \\
P4 & 093054 & 18 & 50 & 3.11 & - & - & - & - \\
\hline
\end{tabular}

Figure 13 further illustrates the impact of the user-definable receiver $\mathrm{iFoV}$ in terms of depth penetration at a near shore transect of pond FP1. In both cases, the point clouds were captured from a flying altitude of $50 \mathrm{~m}$ but with a different iFOV (strip 063419: brown, 6 mrad; strip 093410: blue, $18 \mathrm{mrad}$ ). The larger iFoV leads to a higher depth penetration. In the depicted case of a freshwater pond with an SD of $1.4 \mathrm{~m}$ at the time of data acquisition, the maximum depth is about $2.67 \mathrm{~m}$ with the $6 \mathrm{mrad}$ iFoV and $3.07 \mathrm{~m}$ using the larger $18 \mathrm{mrad}$ iFOV, corresponding to $1.9 \mathrm{SD}$ and $2.2 \mathrm{SD}$, respectively. The gain in the presented case is $40 \mathrm{~cm}(0.3 \mathrm{SD})$ or $15 \%$, respectively. Thus, the manufacturer's specification of $2 \mathrm{SD}$ was verified in the experiment. The wider iFoV also marginally increases the measurement noise, which can be seen from the higher amount of clutter points in Figure 13 as well as from Table 4 (A1, median). This aspect is further discussed in Section 5.4. 


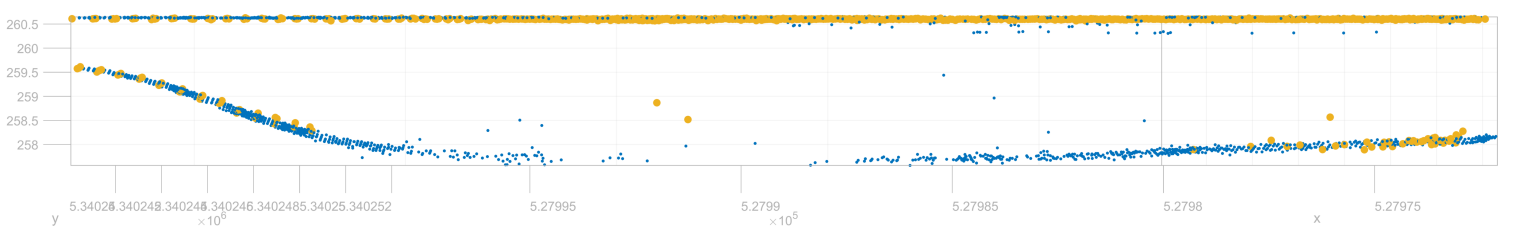

Figure 13. Vertical section of refraction corrected 3D point clouds of strip 063419 (brown, iFoV: $6 \mathrm{mrad}$ ) and 093410 (blue, iFoV: $18 \mathrm{mrad}$ ); flying altitude: $50 \mathrm{~m}$; refraction coefficient used for run-time correction: $(n=1.36)$.

\subsection{Spatial Resolution}

The spatial resolution of any LiDAR system is limited by the size of footprint diameter, which, in turn, is a function of the beam divergence $\gamma$ and the measurement range $R$. In this experiment, a constant beam divergence of $2 \mathrm{mrad}$ was employed to ensure eye safety at the standard flying altitude of $50 \mathrm{~m}$. The footprint diameter $D$ calculates to $D=R \gamma$, i.e., $10 \mathrm{~cm}$ for the standard flight setup in our experiment.

To evaluate the actual footprint diameter, two suitable objects have been chosen and analyzed in detail, namely (i) a linear object and (ii) a sharp angle. Figure 14 shows the 3D point clouds of the study objects in a perspective view (a-c) and a sectional view (d) colorized by signal amplitude. The linear object (rope) does not appear as a confined line of points but rather as a band featuring a width of $30 \mathrm{~cm}$, thus, 3 times the theoretical footprint size.

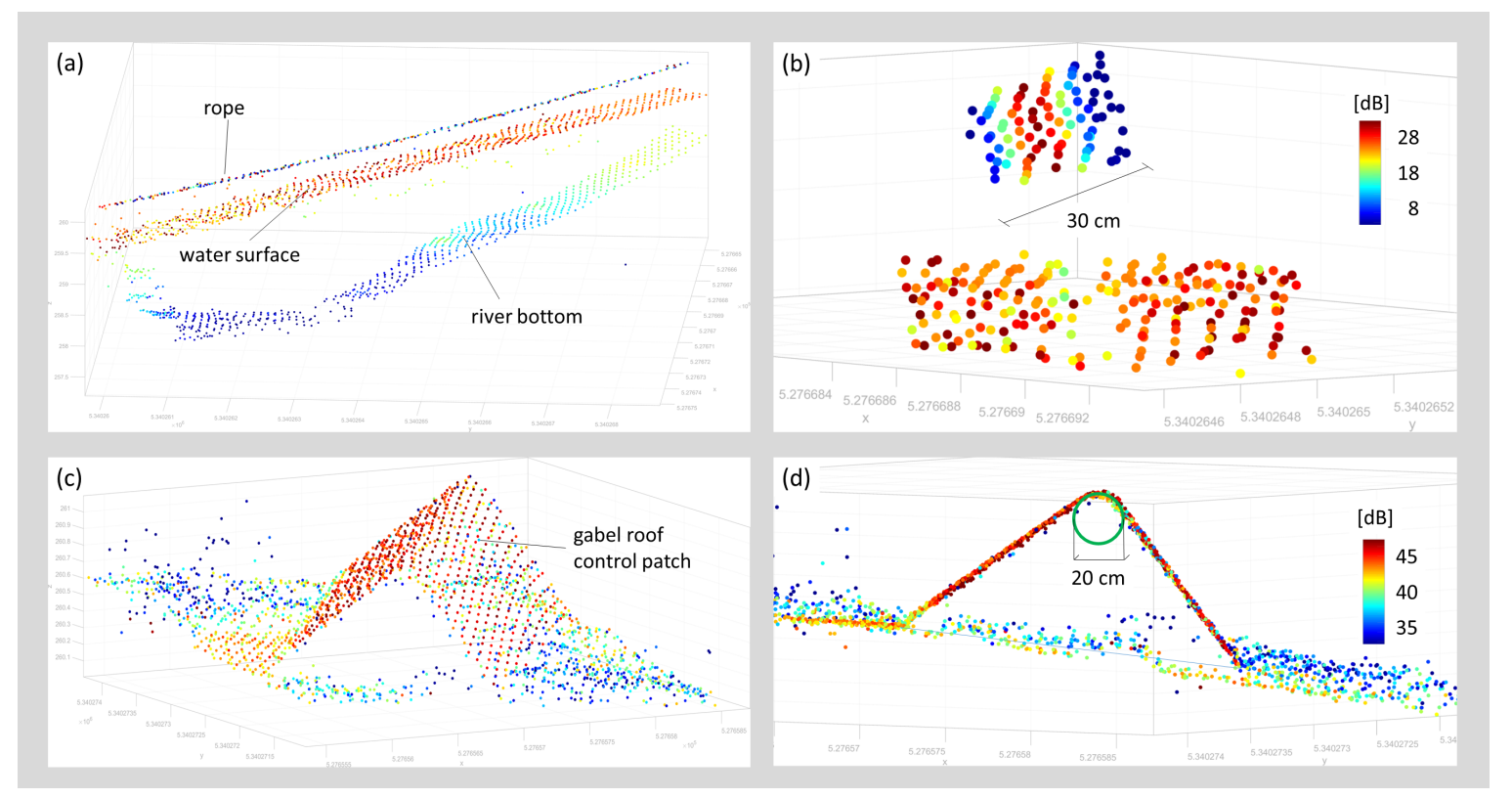

Figure 14. Empirical assessment of spatial resolution; top row: rope spanned across river, bottom row: gable roof shaped control patch; $(\mathbf{a}-\mathbf{c})$ perspective view of 3D point cloud; (d) vertical section; points colored by signal amplitude $[\mathrm{dB}]$.

At the ridgeline of the gable roof-shaped control patch, the points do not form a sharp edge but appear as a circular cylinder featuring a diameter of $20 \mathrm{~cm}$ as the finite laser footprint illuminates both roof sides. This effect is responsible for the larger deviations for all control points along the ridgeline reported in Section 5.2 (cf. Table 5, e.g., point 1022) while all control points, for which the laser footprint is entirely on one side of the wooden panel, exhibit deviations below $1 \mathrm{~cm}$.

It is noted that, as expected, also the receiver iFoV substantially influences the spatial resolution, even for constant beam divergence settings. The plate experiment presented in Section 5.3 shows this clearly. While all plates exhibit an area of $1 \mathrm{~m}^{2}$, increasing the iFoV has a big impact on the apparent 
size of the plate as depicted in the point cloud. For plate P1, for instance, the area covered by laser returns reflecting from the plate with the $18 \mathrm{mrad}$ iFoV setting measures $3.5 \mathrm{~m}^{2}$. This is caused by beam spreading due to volume scattering in the water column. With a larger iFOV, more signal from the periphery of the conical laser beam reaches the detector enabling echo detection even if the plate is only partially within the illuminated footprint. However, full and partial hits of the plates can be distinguished via analysis of the amplitude values. Amplitudes are nearly constant if the entire laser footprint impinges on the plate, and rapidly drop outwards with a decreasing percentage of illuminated plate area (cf. bottom left plot of Figure 12).

\section{Discussion}

The presented compact topo-bathymetric laser scanner exhibits a weight of $12 \mathrm{~kg}$ and a power consumption of $160 \mathrm{~W}$. This makes the instrument suitable for integration on light manned aircraft, gyrocpters, and helicopters as well as on larger UAV platforms, as was the case for our data acquisition. The considerable payload and power consumption, however, limit UAV flight endurance with the selected UAV. The longest net acquisition airtime in our experiment was about 10 min excluding starting, landing, and IMU/GNSS initialization. This might be sufficient endurance for corridor mapping in a visual line of sight (VLOS) context, but poses hard constraints for larger project areas and beyond VLOS operation. Thus, our UAV-borne experiment is regarded as a successful proof-of-concept, but further sensor miniaturization is needed for integration on mainstream UAV platforms like the DJI Matrice 600 Pro or comparable platforms. No matter if the sensor is integrated on a light manned or unmanned aerial platform, in both cases the mobilization costs are considerably lower compared to traditional ALB surveys and smaller aircraft feature a higher maneuverability. The sensor, therefore, constitutes a cost-effective alternative, especially for mapping bathymetry of narrow river channels, as a supplement to area-wide topographic laser scanning which is today often available on a country-wide level.

A major benefit of the sensor design is the adjustable pulse repetition rate, laser beam divergence, and receiver iFoV, making eye-safe operation possible for low flying altitudes like the standard $50 \mathrm{~m}$ altitude in our experiment. Due to the smaller sensor-to-target distances and the narrow laser cone, the resulting nominal laser footprint diameter in the dm-range is much smaller compared to existing topo-bathymetric sensors operated on manned aircraft featuring footprint sizes of about half a meter. This gain in spatial resolution opens new applications in the context of hydraulic engineering (roughness estimation) for reliable flood simulations, eco-hydraulics (habitat modelling), fluvial geomorphology, and many more.

As stated before, the limiting factor for spatial resolution in the lateral direction of the laser beam is the laser footprint, i.e., the illuminated area on the target. As reported in Section 5.4, this is not the same as the area resulting from the vendor specifications. The power distribution in the laser footprint has Gaussian shape and it is common practice to specify the beam diameter by twice the radius where the optical power has decreased by a factor of $1 / e^{2}$. For a beam diameter $w$, the power distribution $I(r)$ as a function of off-axis distance $r$ is given by

$$
I(r)=I_{0} e^{-\left(\frac{2 \sqrt{2}}{w} r\right)^{2}}
$$

with $I_{0}$ the power at the center. The power level at $r=w / 2$ is $0.14 \%$ of the power level at the maximum. Expressing the power level at $r=w / 2$ in Decibels gives

$$
10 \log _{10}\left(\frac{I(0.5 w)}{I_{0}}\right) \approx-8.7 \mathrm{~dB}
$$

A signal causing a return strength in the center of the beam that is more than $8.7 \mathrm{~dB}$ above the receiver detection threshold will cause a detectable signal in an adjacent measurement even when further apart than the nominal beam diameter radius. The effective size of the footprint, thus, is 
determined not only by the properties of the laser beam but also by the sensitivity of the receiver circuitry and the iFOV. A small isolated object will be seen in adjacent laser points until it is too weak to be detected. However, the object will appear with diminishing amplitudes towards the edges (cf. Figure 14b).

The finite footprint and high receiver sensitivity also cause smoothing effects if the target's shape is not flat within the illuminated area. This applies to discontinuities in height (cliff, wall) or slope (sharp edge), or in case of high curvature (e.g., small boulders). In any case, this leads to rounding artifacts as exemplified in Figure $14 \mathrm{~d}$ for a sharp edge. In the context of mapping river channel bathymetry, this limits the ability to precisely reconstruct objects smaller than $\approx 20 \mathrm{~cm}$. While the instrument's spatial resolution is too low for roughness estimation on grain size level, it is suitable for the detection of blocks, boulders, and other flow resistance relevant objects. As an example, the circular underwater reference targets clearly stood out from the surrounding river bottom although they were firmly anchored in the ground and, thus, only protruded from the ground surface by a few $\mathrm{cm}$.

For smooth surfaces, the sensor showed a measurement noise below $1 \mathrm{~cm}$ verified at horizontal asphalt surfaces (cf. surface patch A1 in Figure 8 and Table 4) as well as on tilted surfaces (cf. Table 5, e.g., points 1001-1020). Beyond the local level, this also holds for the strip fitting precision of the entire flight block, which even outperformed comparable data acquisitions with a state-of-the-art topographic UAV laser scanner employed in the same study area in the previous work [66,71]. High relative accuracy is of special importance, e.g., for detailed hydrodynamic-numerical modeling in flat areas where a few $\mathrm{cm}$ can determine whether or not certain areas are flooded.

While the absolute accuracy of the flight block, measured as point-to-plane distances between terrestrially surveyed reference targets and the LiDAR point cloud, is generally better than $3 \mathrm{~cm}$ on land (cf. red dots in Figure 9), systematic deviations were observed for submerged checkpoints. In addition to geometric calibration of the sensor system and (ranging, scanning, lever arms, boresight angles, trajectory), the overall accuracy of LiDAR-derived bathymetry depends on the accuracy of (i) the modeled water surface and (ii) the refraction coefficients for run-time correction. Data analysis has revealed that laser echoes from the water surface are dense (i.e., practically every laser shot returned an echo from the surface) and the signal amplitude is sufficiently strong to enable reliable range measurement. Figures 11 and $14 \mathrm{a}, \mathrm{b}$ illustrate that (i) the recorded signal amplitudes are around $20 \mathrm{~dB}$; (ii) the point density is high; and (iii) the vertical spread is remarkably low. It is well known from literature including our own work $[1,57,77,78]$ that the laser signal reflected from water surfaces is a mixture of reflections from the surface and volume backscattering from the water column beneath the surface. Surface data obtained from conventional green-only ALB sensors operated from manned platforms in flying altitudes of around $600 \mathrm{~m}$ often show a fuzzy appearance. In contrast, surface data acquired in this experiment are concise and the point clouds show a vertical spread of only a few $\mathrm{cm}$. Independent validation of the modeled water surface with terrestrially surveyed checkpoints at the water-land-boundary (cf. Table 5) also confirmed the accuracy of the water surface model. Thus, we rule out that inaccuracies of the modeled water surface are responsible for the detected depth-dependent bias.

Concerning run-time correction, we first started with standard values documented in the literature. [76] reports a valid range of $n=1.329-1.367$, but the upper bound is only valid for extreme salinity and temperature conditions. In recent work, [75] reported that group velocity is relevant for run-time correction of pulsed lasers rather than the phase velocity of the underlying laser wavelength $(\lambda=532 \mathrm{~nm})$. With a respective experiment, they showed that a value of around 1.36 is valid for freshwater conditions. Therefore, this value was also used for run-time correction in this work, but comparison with the reference points still showed a systematic, depth-dependent error. The bias only disappeared when using a hypothetical refraction coefficient of $n=1.42$. As there is no physical explanation for such a high refractive index, the question for the reason of the systematic deviation still remains. Multi-path effects due to complex forward scattering within the water columns are the most likely explanation for the observed phenomenon. As documented in Table 2 and as can be 
seen from the on-site photographs in Figure 6, the turbidity level was high (Secchi depth in the river: $1.1 \mathrm{~m}$ ) due to a thunderstorm event in the days before data acquisition. This resulted in a high load of suspended sediment. Scattering at the sediment particles leads to a widening of the laser footprint, which entails non-linearity of the ray paths leading to elongated path lengths in water, which might result in the observed underestimation of the river bottom height. Following this line of argument, a repeat survey is planned in the winter season 2020 in clear water conditions to verify and quantify the influence of turbidity on the UAV-LiDAR derived depth measurements.

The depth performance of 2 SD stated by the manufacturer was confirmed in the conducted evaluation. All results relied on online waveform processing [62] and did not make use of sophisticated waveform processing $[79,80]$. Processing of data acquired with different iFoV settings confirmed an increased depth performance using the widest possible setting of $18 \mathrm{mrad}$ compared to the default setting of 6 mrad. The gain measures $0.3 \mathrm{SD}$ or $15 \%$ but comes at the price of a reduced spatial resolution as the receiver's perceivable target area is larger, exemplary illustrated in Figure 12 at plate P1. In a practical context, this clearly shows that a trade-off between high spatial resolution and maximum depth performance needs to be found. A potential best practice procedure may include a repeat survey of the same flight lines first with scanner settings optimized for spatial resolution (high PRR, narrow beam divergence and $\mathrm{iFoV}$ ) and second with parameters optimized for maximum depth penetration. With the studied instrument, this can be achieved in a single flight mission as individual sensor settings are feasible on a per flight line basis.

The conducted depth performance assessment based on the four lowered metal plates yielded that plate P4 at a depth of 2.2 SD could not be identified in any of the flight strips including the ones with $18 \mathrm{mrad}$ iFoV. This is astonishing, as the natural bottom of the pond could be measured at approximately the same depth (cf. blue points in Figure 13). By extrapolating the signal amplitude decrease from plate P3 (14.5 dB), enough signal should have been available to also detect P4. One of the plausible reasons is an abrupt turbidity increase within the freshwater pond at a water depth of around $3 \mathrm{~m}$. We consider this the most likely explanation as the pond is mainly used for fishing purposes and the dominating species (Cyprinus carpio) tends to dig into the mud at the bottom of the pond potentially swirling up mud particles.

Beyond the pure sensor settings, an additional increase of depth performance is expected via sophisticated waveform processing. [81] reported an increased areal coverage when employing a surface-volume-bottom based exponential decomposition approach, in both very shallow and deeper water areas. $[5,82]$ use waveform stacking, i.e., averaging of neighboring waveforms, to enhance ALB depth performance reporting an increase of $30 \%$. The presented sensor is specifically well suited for the application of waveform stacking, also referred to as pre-detection averaging, as waveform recording does not depend on a trigger event (i.e., echo detection) during data acquisition but waveforms are continuously stored within a certain range gate. While this is not possible for typical ALB flying altitudes of $600 \mathrm{~m}$ due to storage capacity limits, it is well possible for the shorter ranges in UAV-borne laser bathymetry. By combining the possibilities offered by the sensor (PRR, beam divergence, $\mathrm{iFoV}$ ) with data processing based on the cited strategies, a maximum depth penetration of about 2.9 SD can be expected, but further experiments are required to verify this value.

Further advantages arise from the integration of active and passive sensors in a single hybrid system. Examples for applications benefiting from the concurrent acquisition of laser and image data are water body detection [83] and discharge estimation [46].

\section{Conclusions}

In this paper, we introduced the concept of a novel compact topo-bathymetric laser scanner and presented a comprehensive assessment evaluating measurement noise, strip fitting precision, accuracy compared to terrestrially measured reference data, depth performance, and spatial resolution. With a weight of $12 \mathrm{~kg}$ the sensor is suitable for integration on light manned as well as powerful unmanned platforms, reducing the mobilization costs compared to conventional ALB. The scanner 
features an adjustable pulse repetition rate (50-200 kHz), scan rate (10-100 lines/s), beam divergence (1-6 mrad), and receiver's iFoV (of 3-18 mrad). With nominal flying altitudes from 50-150 m, this enables flexible flight planning and full user control concerning the properties of the resulting 3D point clouds w.r.t. point density, spatial resolution, achievable depth performance, and aerial coverage.

For assessing the overall quality, a flight mission was designed and carried out on 28 August 2019, at the pre-Alpine Pielach River (Austria) with the sensor mounted on an octocopter UAV platform. After geometric calibration and refraction correction, the resulting 3D point clouds were compared to reference points obtained by terrestrial surveys with RTK GNSS and total station. The evaluations exhibited a local measurement noise at smooth asphalt surfaces of 1-3 mm, a relative strip fitting precision of about $1 \mathrm{~cm}$, and an absolute flight block accuracy of $2-3 \mathrm{~cm}$ compared to check points on dry land.

Assessment of the bathymetric accuracy yielded a depth-dependent bias when employing a representative refraction coefficient of $n=1.36$ for run-time correction in water. The maximum deviation of $7.8 \mathrm{~cm}$ at a water depth of $2.1 \mathrm{~m}$ only disappeared when using a hypothetical refraction coefficient of $n=1.42$, which is physically implausible. We hypothesize that the bias results from multi-path effects caused by forward scattering at dissolved sediment particles, as turbidity was high $(\mathrm{SD}: \approx 1.1 \mathrm{~m}$ ) due to thunderstorm events in the days before data acquisition.

Depth performance evaluation, based on four metal plates lowered into a freshwater pond in different depths, confirmed a maximum water penetration depth of 2 SD for the laser echoes derived with online waveform processing. In addition to that, the entire echo waveform is also stored for off-line waveform analysis. Waveform recording does not depend on a triggering event but the entire waveform is rather captured within a user-definable range gate. This enables waveform stacking by summing up the waveforms of neighboring laser shots, which potentially increases the depth performance to 2.5-2.8 SD. Respective experiments addressing these open questions are currently in preparation.

To sum up, the presented compact topo-bathymetric laser scanner is well suited for mapping river channel bathymetry. The sensor system poses an alternative to conventional ALB for mapping smaller rivers and shallow lakes when mounted on flexible UAV-platforms and also for larger coastal environments when integrated on light manned aircraft. One of the main benefits compared to other UAV-based bathymetric laser sensors is the full adjustability of the sensor parameters enabling the end-user to balance accuracy, depth performance, spatial resolution, and aerial coverage.

Author Contributions: G.M. designed the data acquisition (selection of study area, flight mission parameters, reference measurements) and was responsible for data processing (geo-referencing, performance assessment), writing main parts of the text, and supervision the overall manuscript preparation. M.P. provided the text for sensor concept section. R.S. has performed the waveform analysis and other data processing tasks. S.F. and L.N. designed and installed the measurement field for accuracy assessment, and conducted the terrestrial surveying. All authors contributed to the interpretation of the results and to revision of the manuscript. All authors have read and agreed to the published version of the manuscript.

Funding: The presented investigation was partially conducted within the project "Bathymetry by Fusion of Airborne Laser Scanning and Multi-Spectral Aerial Imagery" (SO 935/6-2) funded by the German Research Foundation (DFG). The work of Martin Pfennigbauer and Roland Schwarz was funded by the Austrian Research Funding Agency (FFG) within the project "Aerial search \& Rescue support and supErvision of inAccessible terrains" (AREAS) 86702.

Acknowledgments: The authors acknowledge TU Wien Bibliothek for financial support through its Open Access Funding Program.

Conflicts of Interest: The authors declare no conflict of interest.

\section{References}

1. Guenther, G.C.; Cunningham, A.G.; Laroque, P.E.; Reid, D.J. Meeting the accuracy challenge in airborne lidar bathymetry. In Proceedings of the 20th EARSeL Symposium: Workshop on Lidar Remote Sensing of Land and Sea, Dresden, Germany, 16-17 June 2000. 
2. Parrish, C.E.; Dijkstra, J.A.; O’Neil-Dunne, J.P.M.; McKenna, L.; Pe'eri, S. Post-Sandy Benthic Habitat Mapping Using New Topobathymetric Lidar Technology and Object-Based Image Classification. J. Coast. Res. 2016, 76, 200-208. [CrossRef]

3. Kinzel, P.J.; Legleiter, C.J.; Nelson, J.M. Mapping River Bathymetry With a Small Footprint Green LiDAR: Applications and Challenges. JAWRA J. Am. Water Resour. Assoc. 2013, 49, 183-204. [CrossRef]

4. Mandlburger, G.; Hauer, C.; Wieser, M.; Pfeifer, N. Topo-bathymetric LiDAR for monitoring river morphodynamics and instream habitats-A case study at the Pielach River. Remote Sens. 2015, 7, 6160-6195. [CrossRef]

5. Maas, H.G.; Mader, D.; Richter, K.; Westfeld, P. Improvements in lidar bathymetry data analysis. ISPRS Int. Arch. Photogramm. Remote Sens. Spat. Inf. Sci. 2019, XLII-2/W10, 113-117. [CrossRef]

6. Mitchell, S.E.; Thayer, J.P. Ranging through Shallow Semitransparent Media with Polarization Lidar. J. Atmos. Ocean. Technol. 2014, 31, 681-697. [CrossRef]

7. Goosen, R. This Is How Airborne Multibeam Lidar Coastal Mapping in Paradise is Done. 2019. Available online: https://www.hydro-international.com/content/article/this-is-how-airborne-multibeam-lidar-coast al-mapping-in-paradise-is-done (accessed on 8 February 2020).

8. Fugro. Rapid Airborne Multibeam Mapping System, ALB. 2020. Available online: https://www.fugro. com/about-fugro/our-expertise/innovations/rapid-airborne-multibeam-mapping-system (accessed on 8 February 2020).

9. Riegl. VQ-840-G topo-hydrographic full waveform scanner data sheet. 2020. Available online: http://www.ri egl.com/uploads/tx_pxpriegldownloads/RIEGL_VQ-840-G_Preliminary-Datasheet_2019-09-02.pdf (accessed on 17 March 2020).

10. Murase, T.; Tanaka, M.; Tani, T.; Miyashita, Y.; Ohkawa, N.; Ishiguro, S.; Suzuki, Y.; Kayanne, H.; Yamano, H. A photogrammetric correction procedure for light refraction effects at a two-medium boundary. Photogramm. Eng. Remote Sens. 2008, 74, 1129-1136. [CrossRef]

11. Lyzenga, D.R. Passive remote sensing techniques for mapping water depth and bottom features. Appl. Opt. 1978, 17, 379-383. [CrossRef]

12. Pfennigbauer, M.; Ullrich, A.; Steinbacher, F.; Aufleger, M. High-resolution hydrographic airborne laser scanner for surveying inland waters and shallow coastal zones. Laser Radar Technol. Appl. 2011, 8037, 6. [CrossRef]

13. Tonina, D.; McKean, J.A.; Benjankar, R.M.; Wright, C.W.; Goode, J.R.; Chen, Q.; Reeder, W.J.; Carmichael, R.A.; Edmondson, M.R. Mapping river bathymetries: Evaluating topobathymetric LiDAR survey. Earth Surf. Process. Landforms 2019, 44, 507-520. [CrossRef]

14. Colomina, I.; Molina, P. Unmanned aerial systems for photogrammetry and remote sensing: A review. ISPRS J. Photogramm. Remote Sens. 2014, 92, 79-97. [CrossRef]

15. Schönberger, J.L.; Frahm, J. Structure-from-Motion Revisited. In Proceedings of the 2016 IEEE Conference on Computer Vision and Pattern Recognition (CVPR), Las Vegas, NV, USA, 27-30 June 2016; pp. 4104-4113. [CrossRef]

16. Hirschmuller, H. Stereo Processing by Semiglobal Matching and Mutual Information. IEEE Trans. Pattern Anal. Mach. Intell. 2008, 30, 328-341. [CrossRef]

17. Anderson, K.; Westoby, M.J.; James, M.R. Low-budget topographic surveying comes of age: Structure from motion photogrammetry in geography and the geosciences. Prog. Phys. Geogr. Earth Environ. 2019, 43, 163-173. [CrossRef]

18. Nesbit, P.R.; Hugenholtz, C.H. Enhancing UAV-SfM 3D Model Accuracy in High-Relief Landscapes by Incorporating Oblique Images. Remote Sens. 2019, 11, 239. [CrossRef]

19. Agisoft. Metashape-Photogrammetric Processing of Digital Images and 3D Spatial Data Generation. 2020. Available online: http://www.agisoft.com/ (accessed on 8 February 2020).

20. Pix4D. Pix4Dmapper: Professional Drone Mapping and Photogrammetry Software. 2020. Available online: https://www.pix4d.com/product/pix4dmapper-photogrammetry-software (accessed on 8 February 2020).

21. Rothermel, M.; Wenzel, K.; Fritsch, D.; Haala, N. SURE: Photogrammetric surface reconstruction from imagery. In Proceedings of the Low Cost 3D Workshop, Berlin, Germany, 6-7 December 2012.

22. Mancini, F.; Dubbini, M.; Gattelli, M.; Stecchi, F.; Fabbri, S.; Gabbianelli, G. Using Unmanned Aerial Vehicles (UAV) for High-Resolution Reconstruction of Topography: The Structure from Motion Approach on Coastal Environments. Remote Sens. 2013, 5, 6880-6898. [CrossRef] 
23. Templin, T.; Popielarczyk, D.; Kosecki, R. Application of Low-Cost Fixed-Wing UAV for Inland Lakes Shoreline Investigation. Pure Appl. Geophys. 2018, 175, 3263-3283. [CrossRef]

24. Maas, H.G. On the Accuracy Potential in Underwater/Multimedia Photogrammetry. Sensors 2015, 15, 18140-18152. [CrossRef]

25. Westaway, R.M.; Lane, S.N.; Hicks, D.M. Remote sensing of clear-water, shallow, gravel-bed rivers using digital photogrammetry. Photogramm. Eng. Remote Sens. 2001, 67, 1271-1281.

26. Dietrich, J.T. Bathymetric Structure-from-Motion: extracting shallow stream bathymetry from multi-view stereo photogrammetry. Earth Surf. Process. Landforms 2016, 42, 355-364. [CrossRef]

27. Carrivick, J.L.; Smith, M.W. Fluvial and aquatic applications of Structure from Motion photogrammetry and unmanned aerial vehicle/drone technology. WIREs Water 2019, 6, e1328. [CrossRef]

28. Agrafiotis, P.; Skarlatos, D.; Georgopoulos, A.; Karantzalos, K. Shallow Water Bathymetry Mapping From Uav Imagery Based on Machine Learning. ISPRS Int. Arch. Photogramm. Remote Sens. Spat. Inf. Sci. 2019, XLII-2/W10, 9-16. [CrossRef]

29. Agrafiotis, P.; Karantzalos, K.; Georgopoulos, A.; Skarlatos, D. Correcting Image Refraction: Towards Accurate Aerial Image-Based Bathymetry Mapping in Shallow Waters. Remote Sens. 2020, 12, 322. [CrossRef]

30. Agrafiotis, P.; Skarlatos, D.; Georgopoulos, A.; Karantzalos, K. DepthLearn: Learning to Correct the Refraction on Point Clouds Derived from Aerial Imagery for Accurate Dense Shallow Water Bathymetry Based on SVMs-Fusion with LiDAR Point Clouds. Remote Sens. 2019, 11, 2225. [CrossRef]

31. Mandlburger, G.; Lehner, H.; Pfeifer, N. A Comparison of Single Photon and Full Waveform Lidar. ISPRS Ann. Photogramm. Remote Sens. Spat. Inf. Sci. 2019, 4, 397-404. [CrossRef]

32. Lyzenga, D.R.; Malinas, N.P.; Tanis, F.J. Multispectral bathymetry using a simple physically based algorithm. IEEE Trans. Geosci. Remote Sens. 2006, 44, 2251-2259. [CrossRef]

33. Legleiter, C.J.; Dar, A.R.; Rick, L.L. Spectrally based remote sensing of river bathymetry. Earth Surf. Process. Landforms 2009, 34, 1039-1059. [CrossRef]

34. Legleiter, C.J. Inferring river bathymetry via Image to Depth Quantile Transformation (IDQT). Water Resour. Res. 2016, 52, 3722-3741. [CrossRef]

35. Legleiter, C.J.; Fosness, R.L. Defining the Limits of Spectrally Based Bathymetric Mapping on a Large River. Remote Sens. 2019, 11, 665. [CrossRef]

36. Hernandez, W.J.; Armstrong, R.A. Deriving Bathymetry from Multispectral Remote Sensing Data. J. Mar. Sci. Eng. 2016, 4, 8. [CrossRef]

37. Sagawa, T.; Yamashita, Y.; Okumura, T.; Yamanokuchi, T. Satellite Derived Bathymetry Using Machine Learning and Multi-Temporal Satellite Images. Remote Sens. 2019, 11, 1155. [CrossRef]

38. Gentile, V.; Mróz, M.; Spitoni, M.; Lejot, J.; Piégay, H.; Demarchi, L. Bathymetric Mapping of Shallow Rivers with UAV Hyperspectral Data. In Proceedings of the Fifth International Conference on Telecommunications and Remote Sensing, Milan, Italy, 10-11 October 2016; pp. 43-49. [CrossRef]

39. Birkebak, M.; Eren, F.; Pe'eri, S.; Weston, N. The Effect of Surface Waves on Airborne Lidar Bathymetry (ALB) Measurement Uncertainties. Remote Sens. 2018, 10, 453. [CrossRef]

40. Quadros, N.; Keysers, J. Emerging Trends in Bathymetric Lidar Technology. 2018. Available online: https: //www.hydro-international.com/content/article/emerging-trends-in-bathymetric-lidar-technology (accessed on 8 February 2020).

41. ASTRALiTe. Website of ASTRALiTe, Inc. 2020. Available online: https://www.astralite.net/ (accessed on 8 February 2020).

42. Mitchell, S.; Thayer, J.P.; Hayman, M. Polarization lidar for shallow water depth measurement. Appl. Opt. 2010, 49, 6995-7000. [CrossRef] [PubMed]

43. Wilder Young, J. Little Topo-Bathy Lidar. 2017. Available online: https://lidarmag.com/2017/09/17/little-topobathy-lidar/= (accessed on 8 February 2020).

44. ASTRALite. Press Release: ASTRALiTe Demonstrates Scanning Topo-Bathy LiDAR System on DJI Matrice 600 Pro. 2018. Available online: https://www.businesswire.com/news/home/20181119005609/en/ASTRALiTe -Demonstrates-Scanning-Topo\%E2\%80\%93Bathy-LiDAR-System-DJI (accessed on 8 February 2020).

45. SBG Systems. UAV-Based LiDAR Can Measure Shallow Water Depth. 2019. Available online: http s://spectrum.ieee.org/robotics/drones/uavbased-lidar-can-measure-shallow-water-depth (accessed on 8 February 2020). 
46. Kinzel, P.J.; Legleiter, C.J. sUAS-Based Remote Sensing of River Discharge Using Thermal Particle Image Velocimetry and Bathymetric Lidar. Remote Sens. 2019, 11, 2317. [CrossRef]

47. Mitchell, T. From PILLS To RAMMS. In Proceedings of the 20th Annual JALBTCX Airborne Coastal Mapping and Charting Technical Workshop, South Bend, Indiana, 4-6 June 2019.

48. Zuckerman, S. PILLS 2.5: From Design to Operations. In Proceedings of the 20th Annual JALBTCX Airborne Coastal Mapping and Charting Technical Workshop, South Bend, Indiana, 4-6 June 2019.

49. Fugro. 2020. Available online: https://lidarmag.com/2019/11/13/fugro-ramms-technology-benefits-us-navymapping-system/ (accessed on 8 February 2020).

50. Amuse Oneself Inc. Product website and spec sheet of TDOT GREEN. 2020. Available online: https: //amuse-oneself.com/en/service/tdotgreen (accessed on 8 February 2020).

51. Kasvi, E.; Salmela, J.; Lotsari, E.; Kumpula, T.; Lane, S. Comparison of remote sensing based approaches for mapping bathymetry of shallow, clear water rivers. Geomorphology 2019, 333, 180-197. [CrossRef]

52. Shintani, C.; Fonstad, M.A. Comparing remote-sensing techniques collecting bathymetric data from a gravel-bed river. Int. J. Remote Sens. 2017, 38, 2883-2902. [CrossRef]

53. Eren, F.; Jung, J.; Parrish, C.E.; Sarkozi-Forfinski, N.; Calder, B.R. Total Vertical Uncertainty (TVU) Modeling for Topo-Bathymetric LIDAR Systems. Photogramm. Eng. Remote Sens. 2019, 85, 585-596. [CrossRef]

54. Saylam, K.; Hupp, J.R.; Andrews, J.R.; Averett, A.R.; Knudby, A.J. Quantifying Airborne Lidar Bathymetry Quality-Control Measures: A Case Study in Frio River, Texas. Sensors 2018, 18, 4153. [CrossRef]

55. Steinvall, O.K.; Koppari, K.R.; Karlsson, U.C.M. Experimental evaluation of an airborne depth-sounding lidar. Opt. Eng. 1993, 32, 1307. [CrossRef]

56. Hilldale, R.; Raff, D. Assessing the ability of airborne LiDAR to map river bathymetry. Earth Surf. Process. Landforms 2008, 33, 773-783. [CrossRef]

57. Fernandez-Diaz, J.; Glennie, C.; Carter, W.; Shrestha, R.; Sartori, M.; Singhania, A.; Legleiter, C.; Overstreet, B. Early Results of Simultaneous Terrain and Shallow Water Bathymetry Mapping Using a Single-Wavelength Airborne LiDAR Sensor. IEEE J. Sel. Top. Appl. Earth Obs. Remote Sens. 2014, 7, 623-635. [CrossRef]

58. Fernandez-Diaz, J.C.; Carter, W.E.; Glennie, C.; Shrestha, R.L.; Pan, Z.; Ekhtari, N.; Singhania, A.; Hauser, D.; Sartori, M. Capability Assessment and Performance Metrics for the Titan Multispectral Mapping Lidar. Remote Sens. 2016, 8, 936. [CrossRef]

59. Legleiter, C.J.; Overstreet, B.T.; Glennie, C.L.; Pan, Z.; Fernandez-Diaz, J.C.; Singhania, A. Evaluating the capabilities of the CASI hyperspectral imaging system and Aquarius bathymetric LiDAR for measuring channel morphology in two distinct river environments. Earth Surf. Process. Landforms 2016, 41, 344-363. [CrossRef]

60. Wright, C.W.; Kranenburg, C.; Battista, T.A.; Parrish, C. Depth Calibration and Validation of the Experimental Advanced Airborne Research Lidar, EAARL-B. J. Coast. Res. 2016, 76, 4-17. [CrossRef]

61. Mandlburger, G.; Pfennigbauer, M.; Wieser, M.; Riegl, U.; Pfeifer, N. Evaluation of a novel uav-borne topo-bathymetric laser profiler. Int. Arch. Photogramm. Remote Sens. Spat. Inf. Sci. 2016, XLI-B1, 933-939. [CrossRef]

62. Pfennigbauer, M.; Wolf, C.; Weinkopf, J.; Ullrich, A. Online waveform processing for demanding target situations. Proc. SPIE 2014, 90800J. [CrossRef]

63. Montgomery, D.R.; Buffington, J.M. Channel reach morphology in mountain drainage basins. GSA Bull. 1997, 109, 596-611. [CrossRef]

64. Melcher, A.H.; Schmutz, S. The importance of structural features for spawning habitat of nase Chondrostoma nasus (L.) and barbel Barbus barbus (L.) in a pre-Alpine river. River Syst. 2010, 19, 33-42. [CrossRef]

65. Zitek, A.; Schmutz, S.; Jungwirth, M. Assessing the efficiency of connectivity measures with regard to the EU-Water Framework Directive in a Danube-tributary system. Hydrobiologia 2008, 609, 139-161. [CrossRef]

66. Mandlburger, G.; Pfennigbauer, M.; Riegl, U.; Haring, A.; Wieser, M.; Glira, P.; Winiwarter, L. Complementing airborne laser bathymetry with UAV-based lidar for capturing alluvial landscapes. Proc. SPIE 2015, 9637. [CrossRef]

67. Wieser, M.; Mandlburger, G.; Hollaus, M.; Otepka, J.; Glira, P.; Pfeifer, N. A Case Study of UAS Borne Laser Scanning for Measurement of Tree Stem Diameter. Remote Sens. 2017, 9, 1154. [CrossRef]

68. Pfeifer, N.; Mandlburger, G.; Otepka, J.; Karel, W. OPALS-A framework for Airborne Laser Scanning data analysis. Comput. Environ. Urban Syst. 2014, 45, 2. [CrossRef] 
69. Hutton, J.J.; Gopaul, N.; Zhang, X.; Wang, J.; Menon, V.; Rieck, D.; Kipka, A.; Pastor, F. Centimeter-Level, Robust Gnss-Aided Inertial Post-Processing for Mobile Mapping Without Local Reference Stations. ISPRS Int. Arch. Photogramm. Remote Sens. Spat. Inf. Sci. 2016, XLI-B3, 819-826. [CrossRef]

70. Glira, P.; Pfeifer, N.; Briese, C.; Ressl, C. A Correspondence Framework for ALS Strip Adjustments based on Variants of the ICP Algorithm. PFG Photogramm. Fernerkundung, Geoinf. 2015, 2015, 275-289. [CrossRef]

71. Glira, P.; Pfeifer, N.; Mandlburger, G. Rigorous Strip Adjustment of UAV-based Laserscanning Data Including Time-Dependent Correction of Trajectory Errors. Photogramm. Eng. Remote Sens. 2016, 82, 945-954. [CrossRef]

72. Ressl, C.; Kager, H.; Mandlburger, G. Quality checking of als projects using statistics of strip differences. Int. Arch. Photogramm. Remote Sens. 2008, 37, 253-260.

73. Mandlburger, G.; Hauer, C.; Höfle, B.; Habersack, H.; Pfeifer, N. Optimisation of LiDAR derived terrain models for river flow modelling. Hydrol. Earth Syst. Sci. 2009, 13, 1453-1466. [CrossRef]

74. Westfeld, P.; Maas, H.G.; Richter, K.; Weiß, R. Analysis and correction of ocean wave pattern induced systematic coordinate errors in airborne LiDAR bathymetry. ISPRS J. Photogramm. Remote Sens. 2017, 128, 314-325. [CrossRef]

75. Schwarz, R.; Pfeifer, N.; Pfennigbauer, M.; Mandlburger, G. Depth Measurement Bias in Pulsed Airborne Laser Hydrography Induced by Chromatic Dispersion. IEEE Geosci. Remote Sens. Lett. 2020. submitted.

76. Mobley, C.D. Light and Water: Radiative Transfer in Natural Waters; Academic Press: Cambridge, MA, USA, 1994.

77. Mandlburger, G.; Pfennigbauer, M.; Pfeifer, N. Analyzing near water surface penetration in laser bathymetry-A case study at the River Pielach. ISPRS Ann. Photogramm. Remote Sens. Spat. Inf. Sci. 2013, 2. [CrossRef]

78. Mandlburger, G.; Jutzi, B. On the feasibility of water surface mapping with single photon lidar. ISPRS Int. J. -Geo-Inf. 2019, 8, 188. [CrossRef]

79. Allouis, T.; Bailly, J.S.; Pastol, Y.; Le Roux, C. Comparison of LiDAR waveform processing methods for very shallow water bathymetry using Raman, near-infrared and green signals. Earth Surf. Process. Landforms 2010, 35, 640-650. [CrossRef]

80. Kogut, T.; Bakuła, K. Improvement of Full Waveform Airborne Laser Bathymetry Data Processing based on Waves of Neighborhood Points. Remote Sens. 2019, 11, 1255. [CrossRef]

81. Schwarz, R.; Mandlburger, G.; Pfennigbauer, M.; Pfeifer, N. Design and evaluation of a full-wave surface and bottom-detection algorithm for LiDAR bathymetry of very shallow waters. ISPRS J. Photogramm. Remote Sens. 2019, 150. [CrossRef]

82. Mader, D.; Richter, K.; Westfeld, P.; Weiß, R.; Maas, H.G. Detection and Extraction of Water Bottom Topography From Laserbathymetry Data by Using Full-Waveform-Stacking Techniques. ISPRS Int. Arch. Photogramm. Remote Sens. Spat. Inf. Sci. 2019, XLII-2/W13, 1053-1059. [CrossRef]

83. Tymków, P.; Jóźków, G.; Walicka, A.; Karpina, M.; Borkowski, A. Identification of Water Body Extent Based on Remote Sensing Data Collected with Unmanned Aerial Vehicle. Water 2019, 11, 338. [CrossRef]

(C) 2020 by the authors. Licensee MDPI, Basel, Switzerland. This article is an open access article distributed under the terms and conditions of the Creative Commons Attribution (CC BY) license (http://creativecommons.org/licenses/by/4.0/). 